\title{
Nonlinear dynamic analysis of defective rolling element bearing using Higuchi's fractal dimension
}

\author{
ADITYA SHARMA $^{1}{ }^{\oplus}$, M AMARNATH $^{2}$ and PAVAN KUMAR KANKAR ${ }^{3, *(D)}$ \\ ${ }^{1}$ Department of Mechanical Engineering, Faculty of Engineering, Dayalbagh Educational Institute, \\ Agra 282005, India \\ ${ }^{2}$ Mechanical Engineering Discipline, PDPM Indian Institute of Information Technology, Design and \\ Manufacturing, Jabalpur 482005, India \\ ${ }^{3}$ Discipline of Mechanical Engineering, Indian Institute of Technology, Indore 453552, India \\ e-mail: aditya.me02@gmail.com; amaranth@iiitdmj.ac.in; pavankankar@gmail.com
}

MS received 30 November 2015; revised 10 May 2018; accepted 17 December 2018; published online 11 March 2019

\begin{abstract}
In the present study, localized surface defects are modelled in inner race and outer race, and nonlinear dynamic behaviour of the system has been observed and quantified using Higuchi's fractal dimensions. The Hertzian contact among the rollers and races, clearance and nonlinear damping are considered as sources of nonlinearity. Dynamic responses show system behaviour as periodic, quasi-periodic and chaotic at different rotor speeds. The onset of chaotic motion is identified using Poincaré maps and Higuchi's fractal dimensions. The system shows low peak-to-peak amplitude of vibration responses at higher speeds in the presence of defects. Results also indicate that Higuchi's fractal dimensions can be effectively used as a diagnostic tool for health monitoring.
\end{abstract}

Keywords. Higuchi's fractal dimensions; localized defect; unbalanced rotor; cylindrical roller bearing; Poincaré maps.

\section{Introduction}

Cylindrical roller bearings are frequently used in a wide variety of high-speed applications such as automobiles, gas turbines, space shuttles and others. In today's competitive environment, very precise and safe operations of rotating machinery are of prime importance. This can be achieved by proper condition monitoring of the bearings. Bearings are one of the major sources of nonlinearity in rotating machines, which considerably affect the performance of the system [1]. This leads to focus on the nonlinear analysis of rolling element bearings. The nonlinearity arises in a rotorbearing system due to many imperfections. During continuous operation, many localized faults such as pits, dents, spalls and scratches and distributed faults such as waviness, cage run-out and off-size rolling element arise [1]. In the presence of any defect, the performance of bearing and associated system degrades subsequently and may result in catastrophic failure of the system. Such failures can be avoided by condition monitoring of the bearings. Some remarkable studies have been reported in the literature in which the effects of defects and various other parameters have been considered and analysed on the performance of rolling element bearings. Gupta [2, 3] proposed an

*For correspondence analytical formulation of cylindrical roller bearing. The misalignment of the races was considered in investigations and the author summarized that the geometrical factors do not have any significant effect on the performance of bearing. Later, McFadden and Smith [4, 5] investigated the vibrations of rolling element bearings. The authors performed theoretical and experimental investigations and observed a good correlation between the results. Tandon and Choudhury [6] examined the performance of a deep groove ball bearing in the presence of localized defects. The authors found that peak amplitude of vibrations increased with an increase in load and highest amplitude peaks were observed in the presence of outer race defect. Tiwari and Gupta [7] performed experimental investigations and analysed the effect of unbalance and clearance. The results show that clearance is an important parameter in nonlinear dynamic analysis of rolling element bearings and the system shows unstable nature as the value of clearance increases.

Harsha [8] examined the nonlinear behaviour of the rotor-roller bearing system with unbalanced forces. The author observed period doubling and mechanism of intermittency, which lead to chaos in the system. Lioulios and Antoniadis [9] studied the stability of the rotor-bearing system with speed variations. Authors observed various nonlinear responses, like periodic response, 
unstable periodic response and chaotic responses, but no significant effect of speed variation was identified in the study. Harsha et al [10] and Kankar et al [11] analysed the stability of the rotor-bearing system in the presence of distributed defects and localized defects, respectively. The authors considered stiffness and damping as sources of nonlinearity. Arslan and Aktürk [12] developed an extensive model to study the vibrations of bearings having localized defects. The authors considered the defects in bearing components and summarized that longer preloading results in deformation. Ashtekar et al [13] and Patil et al [14] examined the effect of speed and defect positions in ball bearings. The authors modelled localized defects and concluded that the vibration amplitude rises with defect size. Leblanc et al [15] examined the effect of unbalanced forces, flexible rings and counter-rotating motion on the behaviour of bearings. The authors performed theoretical investigations and observed improved ball harmonics with flexible rings. Sinou [16] studied an unbalanced rotorbearing system having flexible supports. The harmonic balance method was used to analyse the system. This study concluded that the nonlinear contact forces and the whirling motion of the rotor are affected by mass unbalance and radial clearance effect.

In their investigations, Bai et al [17] considered the characteristics of an unbalanced rotor-bearing system experimentally and theoretically. Sub-harmonic resonance responses have been reported in the study, which are responsible for nonlinearity in the system. Patel et al [18] investigated the vibrations of a ball bearing having single and multiple defects on the race surfaces. The authors performed experimental investigations and summarized that multiple-surface defects in outer race surfaces produce severe vibrations, which further result in higher frequencies than those of single-surface defects. An extensive study of the balanced healthy rotor-bearing system with multiple clearances was carried out by Ghafari et al [19]. The authors analysed the effect of clearance and summarized that horizontal and vertical frequency reduced with an increase in clearance. Kankar et al [20] investigated the effect of spall on the vibrations of a balanced horizontal rotor-bearing system. The authors observed a strong chaotic attractor associated with inner race defect and summarized that high-speed rotor results in larger unstable regions. Shao et al [21] considered the effect of localized defects on cylindrical roller bearing theoretically and experimentally using time-varying defect excitation and time-varying contact stiffness excitation methods. Results highlighted that the bearing produced higher amplitudes of vibrations in the presence of defects at the centre of the outer race. The effect of varying number of rollers on the dynamics of cylindrical roller bearing was investigated by Sharma et al [22]. The authors considered nonlinear damping for the examination and concluded that the number of rolling elements affects the stiffness of the system and the effect of varying compliance can be reduced significantly in the presence of more number of rollers.

Nonlinear analysis of bearings includes detailed physical modelling and gives an insight of the system. The reported literature reveals that fewer methodologies have been developed for the investigations of nonlinearity in the rotor-bearing systems. Logan and Mathew [23, 24] utilized correlation dimensions for the examinations of nonlinearity. The authors proposed that correlation dimensions can be effectively used up to a limited number of time series data and are unable to provide precise results beyond this. Jiang et al [25] examined the suitability of correlation dimensions for condition monitoring of gearbox. However, the correlation dimensions are affected significantly in incidence of high noise levels and thus provide less precise results. Yang et al [26] proposed a rolling element bearing fault diagnosis methodology based on fractal dimensions (FDs) and support vector machines (SVMs). The authors used three FDs, viz. capacity dimension, correlation dimension and information dimension, along with various temporal features for the investigations. The results highlighted that diagnosis performance can be improved significantly utilizing the FDs and time domain parameters. Jiang [25] and Ghafari et al [27] used Lyapunov exponent and correlation dimensions to characterize the behaviour of the rotorbearing system. Kappaganthu and Nataraj [28] employed Lyapunov exponents and Poincaré maps to recognize the chaotic regimes in a rotor-bearing system having multiple clearances. The authors identified and summarized various nonlinear regimes like limit cycles, quasi-periodic oscillations and chaos. Gupta et al [29] also utilized Lyapunov exponent as a quantitative measure of chaos in their study and concluded that, in some of the considered cases, Lyapunov exponent is the only tool to observe the nature of the rotor-bearing system. Sharma et al [30] developed an analytical model of the rotor-bearing system for the investigations of nonlinear vibrations. The authors employed Poincaré maps for the analysis of unstable regimes and summarized the nature of the system at various rotational speeds.

Literature indicates that fewer methodologies have been developed to quantify the nonlinearity and there is a great need for another methodology that quantitatively describes nonlinearity in rolling element bearings. FDs have been widely used in many applications [31-35] due to its ability to quantify nonlinearity. The concept of Higuchi's FD is used in this study due to its proved outstanding performance [33]. A two-degree-of-freedom model is developed to study the nonlinear vibrations in the rotor-bearing system. The effect of localized defects, i.e. spall, on the operating surfaces of the cylindrical roller bearing is considered for the analysis. Nonlinear stiffness and nonlinear damping for the unbalanced rotor are considered in the investigations. The Hertzian contact deformation theory is applied to obtain the equations of motion. 


\section{Fractal dimension}

Fractal dimension (FD) is used to quantify the nonlinearity of an irregular time series system. The basic idea about FDs was proposed by Mandelbrot [36]. In general, FD can be defined as a ratio providing a quantitative indicator of complexity comparing by how much factor a pattern closely changes with the measured one. FDs provide a quantitative measure of chaos unlike Fourier transform and bifurcation diagram, which provide a general indication of a change in response from periodic to chaotic and vice versa. Several FD estimation methodologies such as Higuchi's FD [37], Petrosian's FD [38], Katz's FD [39], Detrended Fluctuation Analysis (DFA) [40] and others were successfully employed in various applications such as image characterization [31, 32], biomedical applications $[33,34]$ and ecology [35]. In this study, the concept of Higuchi's fractal dimension (HFD) is employed to quantitatively diagnose the nonlinearity of the rotor-bearing system and is described here.

\subsection{Higuchi's algorithm for FD calculation}

Higuchi's algorithm for FD estimation is based on the calculations of curve length measurement and calculates the FD with high temporal resolution. It evaluates the mean length of the curve by taking a segment of $p$ samples as a unit of measure. HFD estimation methodology requires the following steps for the calculation of FDs [34].

Step 1: Define a finite set of time series data at a regular interval as

$$
q(1), q(2), q(3), \ldots, q(M), \ldots, q(N)
$$

where $M=1,2,3, \ldots, N$.

In this study, the time series is successive displacement values in horizontal and vertical directions.

Now, construct a new time series $q_{p}^{v}$, for a range of $p$ values from 1 to $p_{\max }$, as

$$
q_{p}^{v}=q(v), q(v+p), q(v+2 p), \ldots, q\left(v+\operatorname{int}\left(\frac{N-v}{p}\right) p\right)
$$

where $v=1,2,3, \ldots, p$.

Step 2: Calculate the length $\left(L_{v}(p)\right)$ of each curve $q_{p}^{v}$ as

$$
L_{v}(p)=\left[\left(\sum_{M=1}^{\operatorname{int}\left(\frac{N-v}{p}\right)}|q(v+M p)-q(v+(M-1) p)|\right) \frac{N-1}{\operatorname{int}\left(\frac{N-v}{p}\right) p}\right] p^{-1}
$$

where the term $(N-1)\left(\operatorname{int}\left(\frac{N-v}{p}\right) p\right)^{-1}$ indicates the normalization factor for the curve length of $q_{p}^{v}$.

Step 3: Estimate the mean length of the curve for each value of $p,\langle L(p)\rangle$, as the average value over $p$ sets of $L_{v}(p)$, for $v=1,2, \ldots, p$ and repeat the iteration for $p$ ranging from 1 to $p_{\max }$.

Step 4: If $\langle L(p)\rangle \propto(p)^{-F D}$, then the curve is fractal with dimension FD.

In the present study, the value of $p_{\max }$ is obtained from a wide range of $p$ values, ranging from 1 to 40,000, in each of the horizontal and vertical directions, using the method proposed by Polychronaki et al [34].

The HFDs are calculated for each of $p$ values for a synthetic signal (Weierstrass sequence). To evaluate the accuracy of the proposed algorithm, relative error $\left(E_{R}\right)$ is calculated for various $p_{\max }$ values as follows:

$$
E_{R}=F D_{e s t}-F D_{t h} .
$$

The synthetic Weierstrass sequence having $F D_{t h}=1.5$ is used in the present study and shown in figure 1 . The plot of relative error for Weierstrass sequence is shown in figure 2 . It can be easily observed from figure 2 that relative error is minimum for $p_{\max }=7,747$ (as $p$ has a wide range from 1 to 40,000 , only a segment of this range in which $E_{R}$ is minimum is shown here). The values smaller and higher than 7,747 provide large relative error for the dataset. Hence HFD is estimated using $p_{\max }=7,747$ in this study.

It takes ample amount of time for the analysis of FDs, which depends upon the number of samples in the data. However, the accuracy of FDs is correlated with the number of samples. In other words, larger the sample size, higher the computation time and higher the accuracy. The value of FDs for a 2-dimensional time series data varies between 1 and 2, where the FDs near 1 indicate the periodic nature and FDs near 2 indicate the chaotic nature of the system [33, 41].

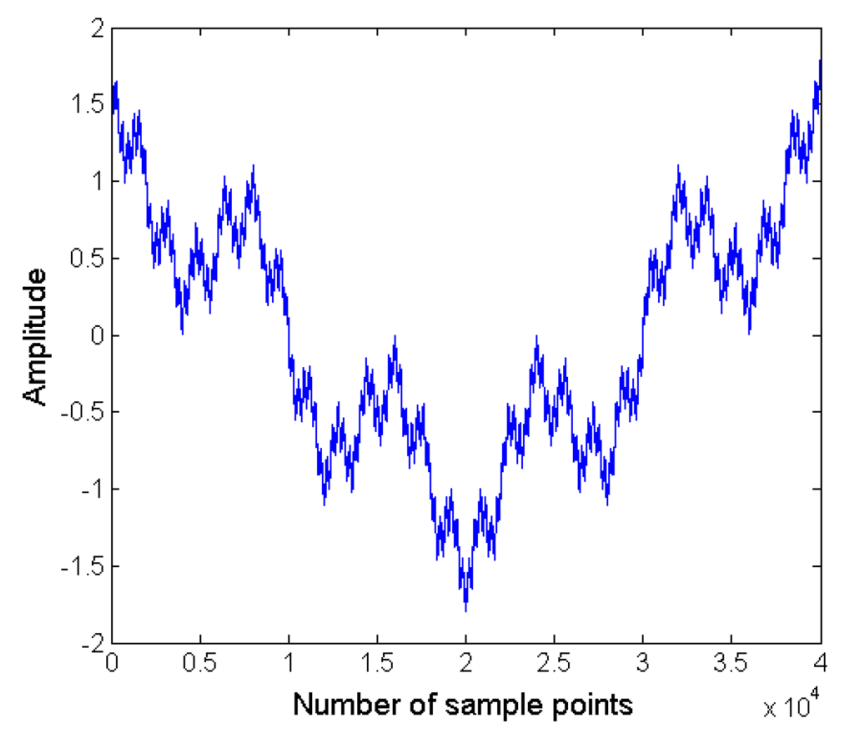

Figure 1. Weierstrass function for fractal dimension $\left(F D_{t h}=1.5\right)$. 


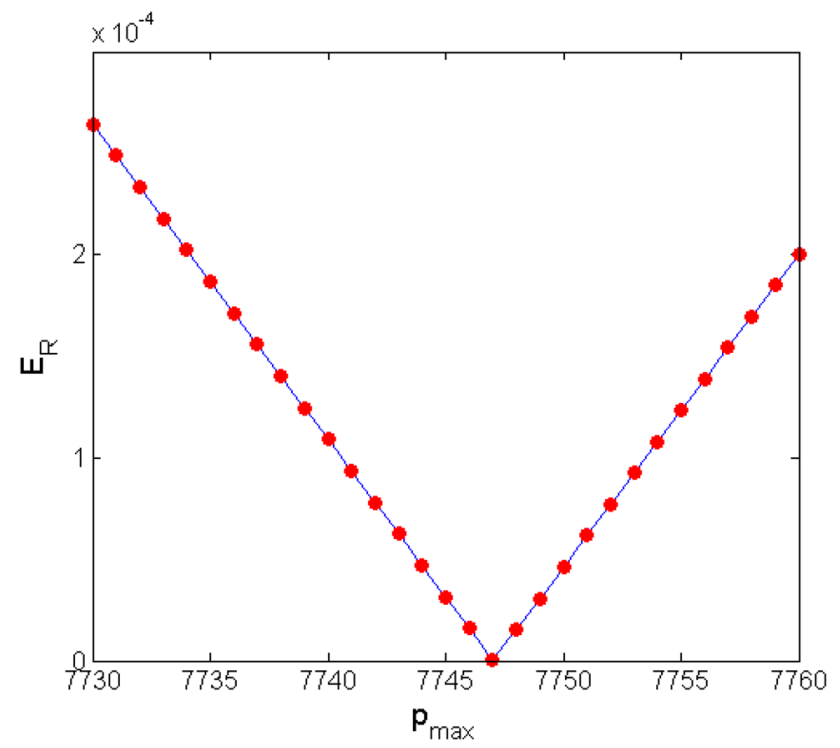

Figure 2. Relative error $\left(E_{R}\right)$ for Higuchi's fractal dimension estimations with $p_{\max }$.

\section{Mathematical model description}

The outlines of a cylindrical roller bearing are shown in figure 3a. For analysing the vibration characteristics of a rotor-bearing system, the bearing can be modelled as a spring-mass-damper system, as shown in figure $3 \mathrm{~b}$, in which the outer race is rigidly fixed in support and the inner race is fixed with a rotating shaft. A constant radial vertical load is assumed to be acting on the system. Other parameters and physical values corresponding to the analysis are listed in table 1. In the study, the bearing components are considered as mass-less and rollers as nonlinear contact
Table 1. Geometrical and physical values of bearing.

\begin{tabular}{lc}
\hline Parameter & Value \\
\hline Bearing specification & $207 \mathrm{ECP}$ \\
Mass of rotor $(m)$ & $5.86 \mathrm{~kg}$ \\
Radial load $(W)$ & $57.4866 \mathrm{~N}$ \\
Radius of inner race $\left(R_{i r}\right)$ & $22 \mathrm{~mm}$ \\
Radius of outer race $\left(R_{\text {or }}\right)$ & $32 \mathrm{~mm}$ \\
Pitch circle radius $\left(R_{p}\right)$ & $27 \mathrm{~mm}$ \\
Radius of roller $\left(R_{r}\right)$ & $5 \mathrm{~mm}$ \\
Effective length of roller $\left(L_{u}\right)$ & $10.15 \mathrm{~mm}$ \\
Number of rollers $\left(N_{r}\right)$ & 14 \\
Contact angle $(\beta)$ & $0^{\circ}$ \\
Radial clearance $\left(R_{c r}\right)$ & $0.025 \mathrm{~mm}$ \\
Damping factor $(c)$ & $450 \mathrm{Ns} / \mathrm{m}$ \\
\hline
\end{tabular}

springs. Thus, under dynamic conditions, the system experiences nonlinear vibrations. The elastic deformation between rollers and races results in nonlinear deformation of bearing components and is calculated using Hertzian deformation theory. The other sources of stiffness variation in the model are the presence of localized defects at inner and outer race surfaces, the finite number of rollers and positive internal radial clearance.

Following assumptions have been made in this work for modelling the system:

(i) all bearing components are perfectly rigid and no slip occurs in between;

(ii) the deformation of bearing components occurs according to elastic contact theory of Hertz only and small elastic deformations of the rolling elements and races have been taken into account;

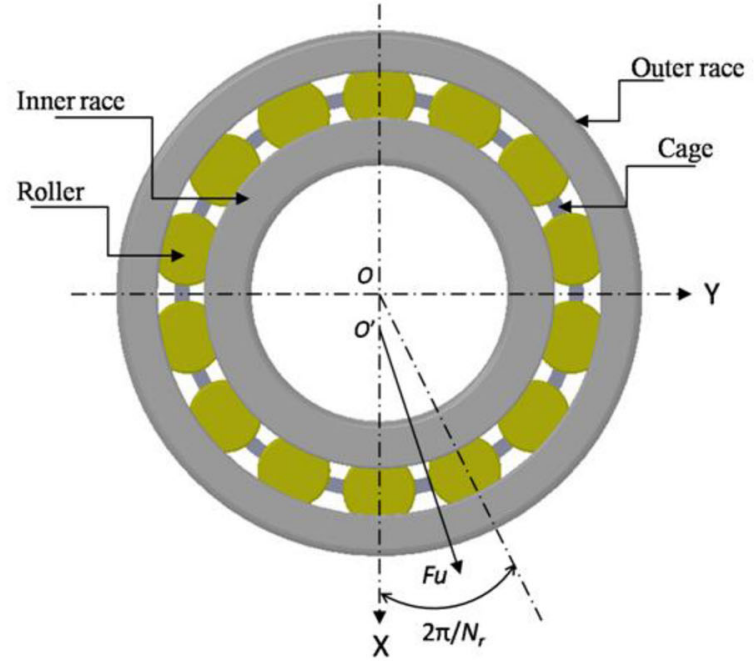

(a)

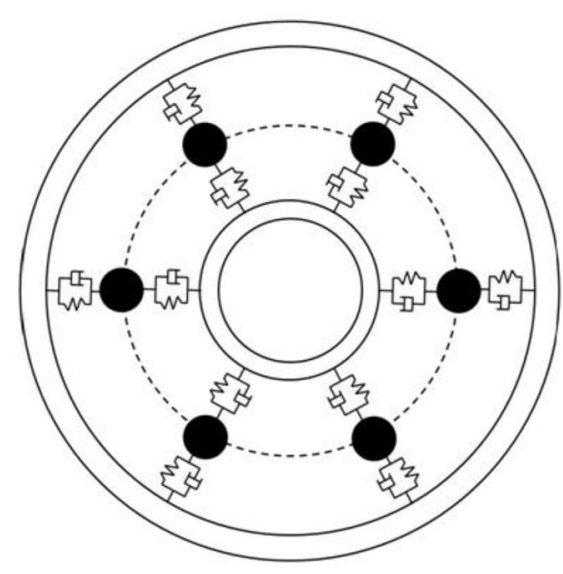

(b)

Figure 3. (a) Representation of cylindrical roller bearing and (b) spring-mass-damper model of the bearing. 
(iii) all bearing components and rotor have motion in the plane of bearing only and the angular velocity of the cage remains constant;

(iv) all the thermal effects are neglected for the analysis.

\subsection{Contact stiffness}

The total deformation $(\delta)$ at two contact points of a roller with the raceways is given by [42]

$$
\delta=\frac{8.10}{10^{5}} \frac{Q^{0.925}}{L_{u}^{0.85}}(\mathrm{~mm})
$$

where $L_{u}$ is effective length of the roller and $Q$ is the contact force, which is given as

$$
Q=k \delta^{1.08}(\mathrm{~N}) .
$$

The nonlinear stiffness for cylindrical roller bearing is therefore given as

$$
k=26200 L_{u}^{0.92}\left(\mathrm{~N} / \mathrm{mm}^{1.08}\right) .
$$

\subsection{Restoring force}

The local contact force at the $j^{\text {th }}$ roller and corresponding deformation can be expressed according to Hertzian theory as

$$
F_{\theta_{j}}=k\left(\delta_{\theta_{j}}\right)^{1.08} .
$$

The total deformation of the $j^{\text {th }}$ roller considering internal radial clearance $\left(R_{c r}\right)$ and radial deflection is given as

$$
\delta_{\theta_{j}}=x \cos \theta_{j}+y \sin \theta_{j}-R_{c r} .
$$

Thus, the total restoring force acting on the bearing in $X$ and $Y$ directions can be expressed as

$$
\begin{aligned}
Z_{x} & =\sum_{j=1}^{N_{r}} k\left[\left(x \cos \theta_{j}+y \sin \theta_{j}\right)-\left(R_{c r}\right)\right]_{+}^{1.08} \cos \theta_{j} \\
Z_{y} & =\sum_{j=1}^{N_{r}}\left[\left(x \cos \theta_{j}+y \sin \theta_{j}\right)-\left(R_{c r}\right)\right]_{+}^{1.08} \sin \theta_{j}
\end{aligned}
$$

where the ' + ' sign as subscript indicates that if the term inside the bracket is greater than zero, the roller at angular position $\theta_{j}$ is loaded and gives rise to restoring force and if the term inside the bracket is otherwise, then the roller is not in the load zone and the restoring force is set to zero.

\subsection{Damping force}

In the present study, nonlinear damping is considered to be acting due to the lubricant and it is assumed to behave in a
Newtonian way. Hence, a viscous damping model is adopted in which the dissipative forces are considered to be proportional to the time derivative of the mutual approach [20]. Therefore, the resulting equation is given as

$$
\overrightarrow{P_{d_{j}}}=Z\left(\delta_{\theta_{j}}\right) \cdot \dot{\delta}_{\theta_{j}}
$$

where $\delta_{\theta_{j}}$ is the total deformation of the $j^{\text {th }}$ roller, which represents the change in curvature of the $j^{\text {th }}$ roller in loading and no-load conditions [43], as indicated in figure 4. $Z\left(\delta_{\theta_{j}}\right)$ is a function of material properties of two elastic bodies, contact surface, velocities and contact geometry and lubricant properties.

Thus the governing equations of motion of the system become

$$
\begin{aligned}
& m \ddot{x}+\sum_{j=1}^{N_{r}} \overrightarrow{P_{d_{j}}} \cos \theta_{j} \\
&+\sum_{j=1}^{N_{r}} k\left[\left(x \cos \theta_{j}+y \sin \theta_{j}\right)-\left(R_{c r}\right)\right]_{+}^{1.08} \cos \theta_{j} \\
&=W+U_{f} \cos (\omega t) \\
& m \ddot{y}+\sum_{j=1}^{N_{r}} \overrightarrow{P_{d_{j}}} \sin \theta_{j}+\sum_{j=1}^{N_{r}} k\left[\left(x \cos \theta_{j}+y \sin \theta_{j}\right)-\left(R_{c r}\right)\right]_{+}^{1.08} \\
& \sin \theta_{j}=U_{f} \sin (\omega t) .
\end{aligned}
$$

\subsection{Localized defects}

In rolling element bearings, repeated compressive stresses are developed, which result in fatigue cracks on the operating surfaces. During operation over a period of time, these cracks propagate and result in spalling on the surfaces of races or rolling elements. Spalling leaves deeper cavities at contact surfaces with a depth of 20-100 $\mu \mathrm{m}$ [44]. In the present study, a spall is considered and modelled on races as shown in figure 5 .

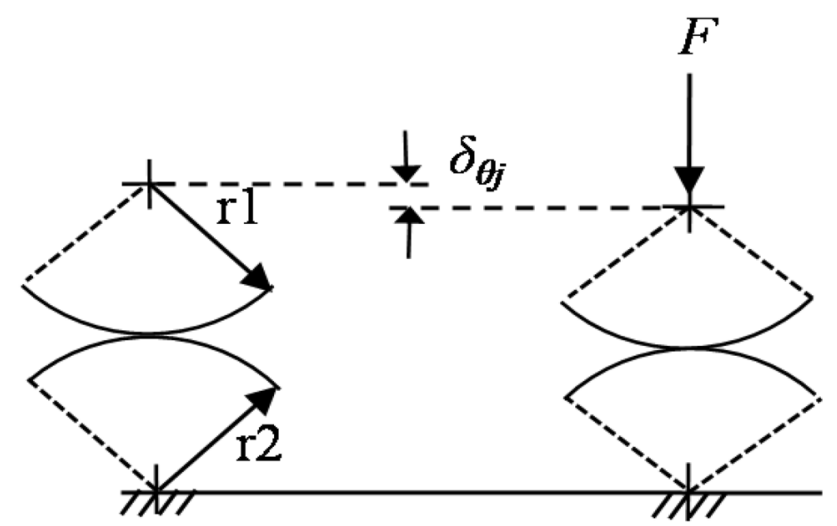

Figure 4. Deformation of contact surfaces in no-load and loading conditions. (Reconstructed from [43]) 


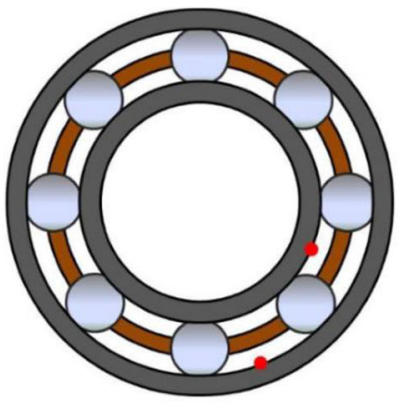

(a)

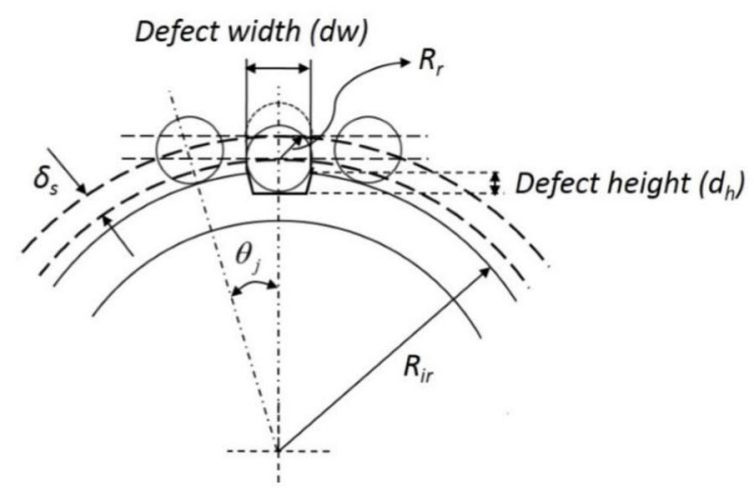

(c)

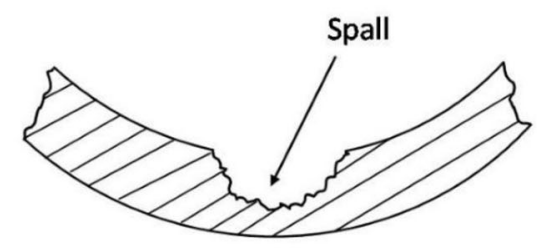

(b)

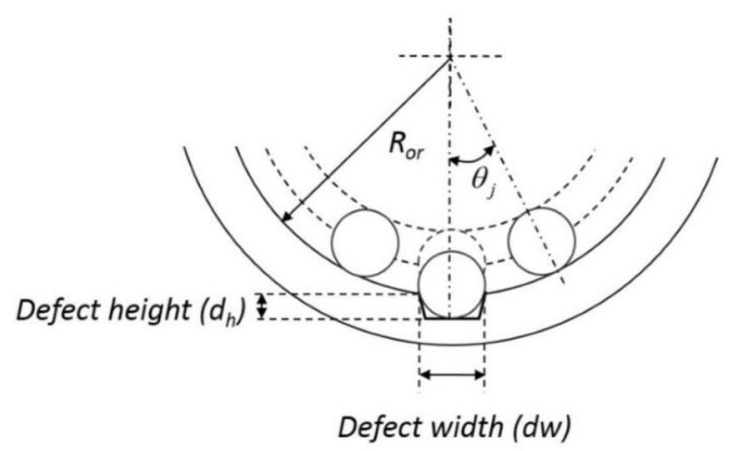

(d)

Figure 5. Schematic representation of (a) bearing having defects, (b) spall on bearing component, (c) defect on the inner race and (d) defect on the outer race.

3.4a Inner race defect: As mentioned earlier, the inner race is assumed to be rigidly fixed with the rotating shaft and roller centre rotates at the speed of the cage; thus the contact angle is

$$
\theta_{j}=\frac{2 \Pi}{N_{r}}(j-1)+\left(\omega_{c g}-\omega_{i r}\right) t
$$

As the defect is at inner race surface, it rotates at speed $\omega_{i r}$. When the roller passes over the defect, it results in additional deflection, which will be equal to ' $\delta_{s}$ '. In other words, an additional deflection ' $\delta_{s}$ ' will be obtained in contact deformation when the angle of defect $\left(\phi_{\text {dir }}\right)$ coincides with the contact angle $\left(\theta_{j}\right)$ of the $j^{\text {th }}$ roller.

The angle of defect at inner race surface can be expressed as

$$
\phi_{d i r}=\left[\omega_{i r} \pm \frac{d w}{2 R_{i r}}\right] .
$$

The angular position $\left(\theta_{j}\right)$ of the $j^{\text {th }}$ roller in defect zone can be expressed as

$$
\left(\omega_{i r} t-\frac{d w}{2 R_{i r}}\right) \leq \theta_{j} \leq\left(\omega_{i r} t+\frac{d w}{2 R_{i r}}\right) . .
$$

3.4b Outer race defect: In this study, outer race is considered to be stationary, having a localized defect.
Therefore, the angular position of the defect will not change, like that of inner race. Whenever a roller passes over the defect, it will result in additional deflection ' $\delta_{s}$ ', and it will be obtained when the angle of defect of outer race $\left(\phi_{d o r}\right)$ coincides with the contact angle of the roller $\left(\theta_{j}\right)$. Mathematically, the angle of the defect at the outer race surface can be expressed as

$$
\phi_{d o r}=\left[\phi_{d o r} \pm \frac{d w}{2 R_{o r}}\right]
$$

and the contact angle is

$$
\theta_{j}=\frac{2 \Pi}{N_{r}}(j-1)+\omega_{c g} t
$$

Hence, the angular position of the $j^{\text {th }}$ roller in the defect zone can be expressed as

$$
\left(\phi_{d o r}-\frac{d w}{2 R_{o r}}\right) \leq \theta j \leq\left(\phi_{d o r}+\frac{d w}{2 R_{o r}}\right) .
$$

\subsection{Equations of motion}

Considering the deflection ' $\delta_{s}$ ', as mentioned in section 3.4; substituting it in Eqs. (13) and (14), respectively, gives 


$$
\begin{gathered}
m \ddot{x}+\sum_{j=1}^{N_{r}} \overrightarrow{P_{d_{j}}} \cos \theta j+\sum_{j=1}^{N_{r}} k[(x \cos \theta j+y \sin \theta j) \\
\left.-\left(R_{c r}+\delta_{s}\right)\right]_{+}^{1.08} \cos \theta j=W+U_{f} \cos (\omega t), \\
m \ddot{y}+\sum_{j=1}^{N_{r}} \overrightarrow{P_{d_{j}}} \sin \theta_{j}+\sum_{j=1}^{N_{r}} k[(x \cos \theta j+y \sin \theta j) \\
\left.-\left(R_{c r}+\delta_{s}\right)\right]_{+}^{1.08} \sin \theta j=U_{f} \sin (\omega t) .
\end{gathered}
$$

Equations (21) and (22) are the governing nonlinear secondorder coupled equations of motion of the system accounting for inertia force, damping force, restoring force and invariable vertical force on inner race having the parametric effect and summation term. As an inevitable effect, unbalanced forces cannot be eliminated in the rotor-bearing system. In this study, an unbalanced force $\left(U_{f}\right)$ is considered as $5 \%$ of the radial load $(W)$ acting on the rotor-bearing system.

\section{Results and discussion}

As mentioned earlier, during continuous operation, localized defects such as spall may arise at the operating surfaces of the bearing and affect the normal operation of the rotor-bearing system. To examine the behaviour of the rotor-bearing system in the presence of localized defects, the prior knowledge of such a type of system is very important. In the present study, the combined effects of unbalanced forces and localized defects on the races of bearing at various speeds are taken into account for the analysis of nonlinear vibrations.

Figure 6 shows the responses of the healthy rotor-bearing system. It indicates stable nature up to $1620 \mathrm{rpm}$. The nature of the solution of the system in this region at $800 \mathrm{rpm}$ is shown in figure 6a. The peak amplitudes of vibration are detected in frequency spectrums at superharmonics of varying compliance $(\mathrm{VC})$ frequency as $10 \mathrm{VC}$ (763.3 rad/s) and $2 V C(156.7 \mathrm{rad} / \mathrm{s})$, respectively, in horizontal and vertical directions. Other major peaks are perceived at $V C, 2 V C, 3 V C$ and $11 V C$. The Poincaré maps indicate the stable nature with multi-orbit periodic nature of the system. The HFDs are obtained as 1.0379 and 1.0910, respectively, in horizontal and vertical directions and confirm the stable nature of the system. As the speed changes, the system loses its stability and enters an unstable region. The system shows unstable nature from 1630 to $2090 \mathrm{rpm}$ and this region is identified as the first unstable region. The unstable nature of the system is due to the change in Hopf bifurcation with speed variation. Response plots of the system in this region at $1700 \mathrm{rpm}$ are shown in figure $6 \mathrm{~b}$, where the fractal natures of Poincaré maps show the chaotic nature of the system. The HFDs are employed to quantify the nonlinearity of the system at this speed and calculated as 1.7552 and 1.7619 , respectively, in horizontal and vertical directions. It indicates the chaotic nature of the system.
As the speed increases, the system regains its stability at $2125 \mathrm{rpm}$; this remains up to $2480 \mathrm{rpm}$ and there are period-doubling bifurcations. Response plots in this region at $2480 \mathrm{rpm}$ are shown in figure 6c. The peak amplitudes of vibrations in frequency spectrums are found at $3 \mathrm{VC}$ (713.6 rad/s) and $0.5 V C(122.7 \mathrm{rad} / \mathrm{s})$, respectively, for horizontal and vertical directions and other major peaks can be noticed at $V C$ and $2.5 \mathrm{VC}$. The closed orbit nature of the Poincaré maps indicates the stable nature of the system. The HFDs of the system at this speed are found to be 1.0166 and 1.0271, respectively, in horizontal and vertical directions and confirm the periodic nature of the system. As the speed is further increased to $2490 \mathrm{rpm}$, the system loses its stability. The system enters chaotic region due to the sudden attack of chaotic attractor (as it crosses the eigenvalue of +1 ) and remains in the unstable region up to $2600 \mathrm{rpm}$. This region is identified as the second unstable region. In this unstable region, the response plots of the system at $2590 \mathrm{rpm}$ are shown in figure $6 \mathrm{~d}$, where the peak amplitudes of vibrations are perceived at $3 \mathrm{VC}(716.6 \mathrm{rad} / \mathrm{s})$ and $0.5 \mathrm{VC}(126.7 \mathrm{rad} / \mathrm{s})$ in frequency spectrums, respectively, for horizontal and vertical directions. The fractal nature of Poincaré maps shows the chaotic nature of the system and the HFDs are obtained as 1.7351 and 1.7233, respectively, in horizontal and vertical directions.

With further increment in speed to $2610 \mathrm{rpm}$, the system comes out of the chaotic regime and regains stability. The system exhibits a stable nature up to $3350 \mathrm{rpm}$. Behaviour of the system in this region at $3200 \mathrm{rpm}$ is shown in figure $6 \mathrm{e}$, where the peak amplitudes are perceived at $2.5 \mathrm{VC}$ (763.3 $\mathrm{rad} / \mathrm{s})$ and $0.5 \mathrm{VC}(156.7 \mathrm{rad} / \mathrm{s})$, respectively, in horizontal and vertical directions and other major peaks are found at $V C$. The HFDs at $3200 \mathrm{rpm}$ are obtained as 1.0937 and 1.0940, respectively, in horizontal and vertical directions. The system exhibits quasi-periodic nature with further increment in speed from 3380 to $3500 \mathrm{rpm}$. Response plots of the system in this region at $3500 \mathrm{rpm}$ are shown in figure $6 \mathrm{f}$. The net-structured shape of Poincaré maps at $3500 \mathrm{rpm}$ shows the unstable nature of the system. The highest amplitudes of vibration at $3500 \mathrm{rpm}$ are noticed at $V C(332.7 \mathrm{rad} / \mathrm{s})$ and $0.5 V C(170 \mathrm{rad} / \mathrm{s})$, respectively, in horizontal and vertical directions and other major peaks are found at $0.5 \mathrm{VC}, 1.5 \mathrm{VC}$ and $2 \mathrm{VC}$ in horizontal direction as indicated in figure $6 \mathrm{f}$. The HFDs of the system in this unstable region at $3500 \mathrm{rpm}$ are found to be 1.4900 and 1.5821 , respectively, in horizontal and vertical directions and show the nature of the system to be between periodic and aperiodic solutions.

As the speed is further increased to $3520 \mathrm{rpm}$, the system comes out of the unstable region. The system shows stable nature from 3520 to $8350 \mathrm{rpm}$. Response plots of the system in this region at 4200 and $8200 \mathrm{rpm}$ are shown in figure $6 \mathrm{~g}$ and $\mathrm{h}$, respectively. The peak amplitudes of vibration at $4200 \mathrm{rpm}$ are found at $V C$ (404.5 rad/s) for both horizontal and vertical responses. The HFDs are found to be 1.0168 and 1.0142, respectively, in horizontal and vertical 

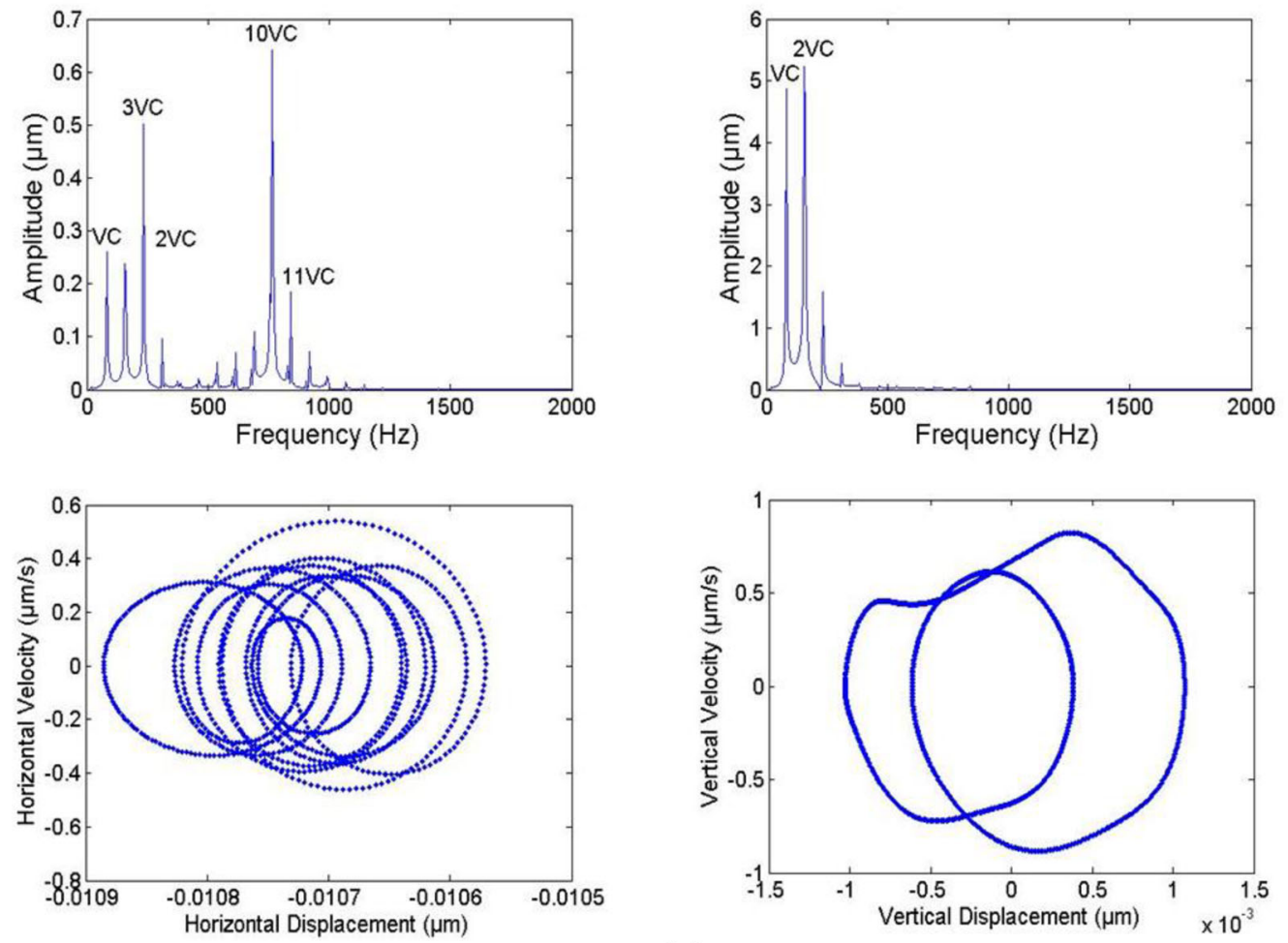

(a)
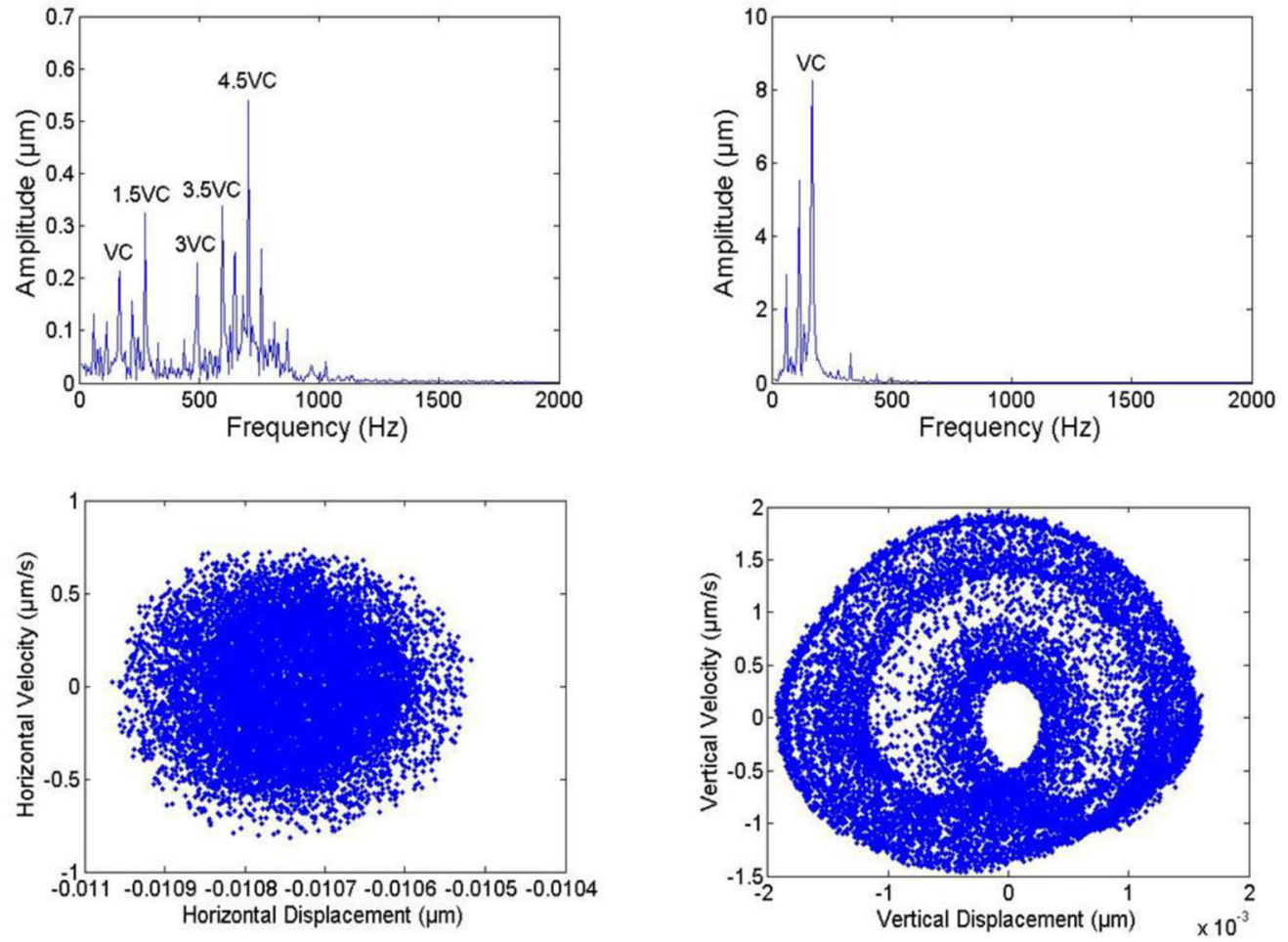

(b)

Figure 6. Response plots of healthy bearing at (a) $800 \mathrm{rpm}$, (b) $1700 \mathrm{rpm}$, (c) $2480 \mathrm{rpm}$, (d) $2590 \mathrm{rpm}$, (e) $3200 \mathrm{rpm}$, (f) $3500 \mathrm{rpm}$, (g) $4200 \mathrm{rpm}$, (h) $8200 \mathrm{rpm}$, (i) $9500 \mathrm{rpm}$ and (j) $10000 \mathrm{rpm}$. 

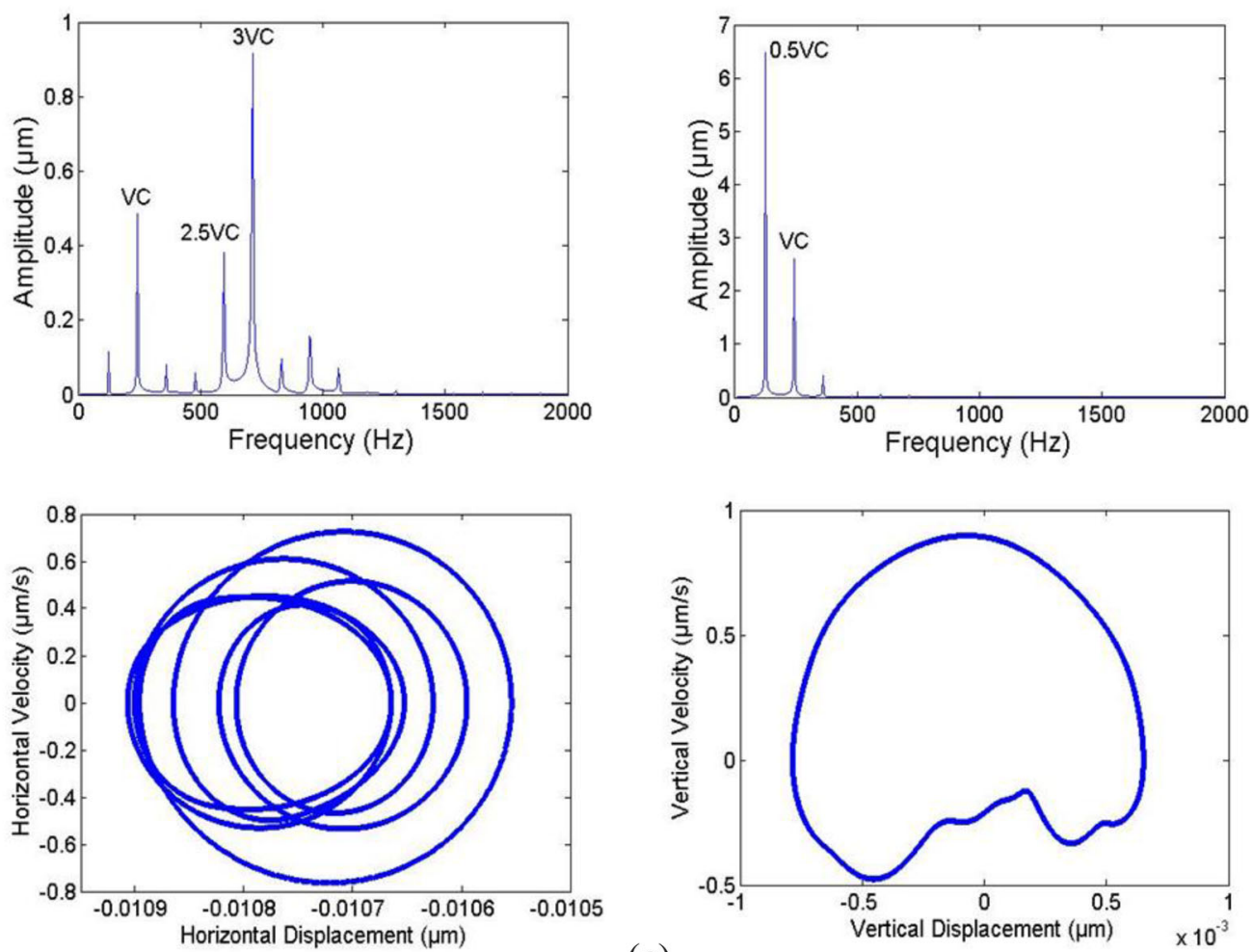

(c)
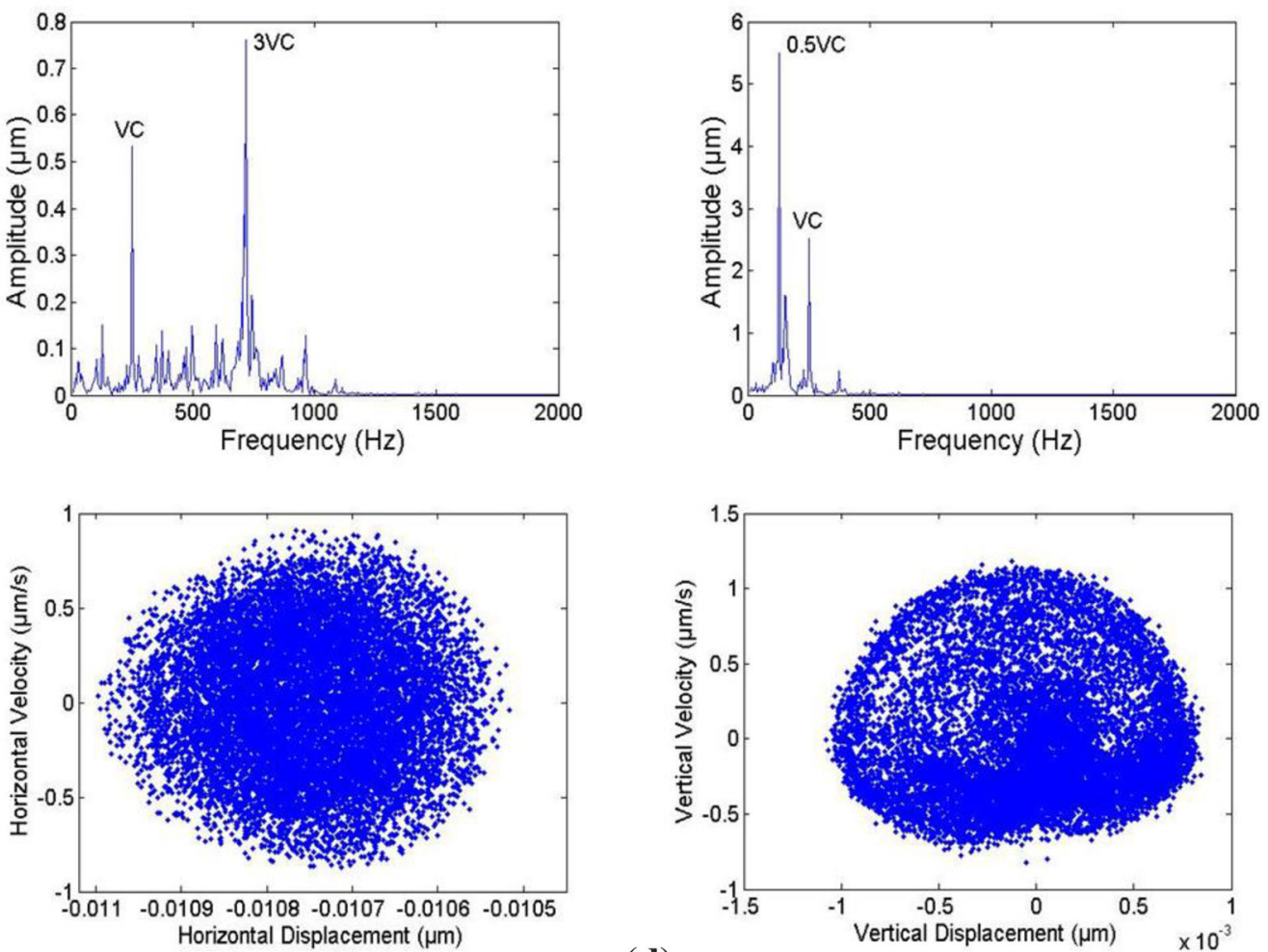

(d)

Figure 6. continued

directions. They indicate the stable nature of the system. For $8200 \mathrm{rpm}$, the peaks are observed in frequency spectrums at $V C(783.3 \mathrm{rad} / \mathrm{s})$ for both horizontal and vertical responses and the other peaks are perceived at $2 V C(1566.6 \mathrm{rad} / \mathrm{s})$. The HFDs for this speed are found to be 1.0373 and 1.3787 , respectively, in horizontal and vertical directions. Another 

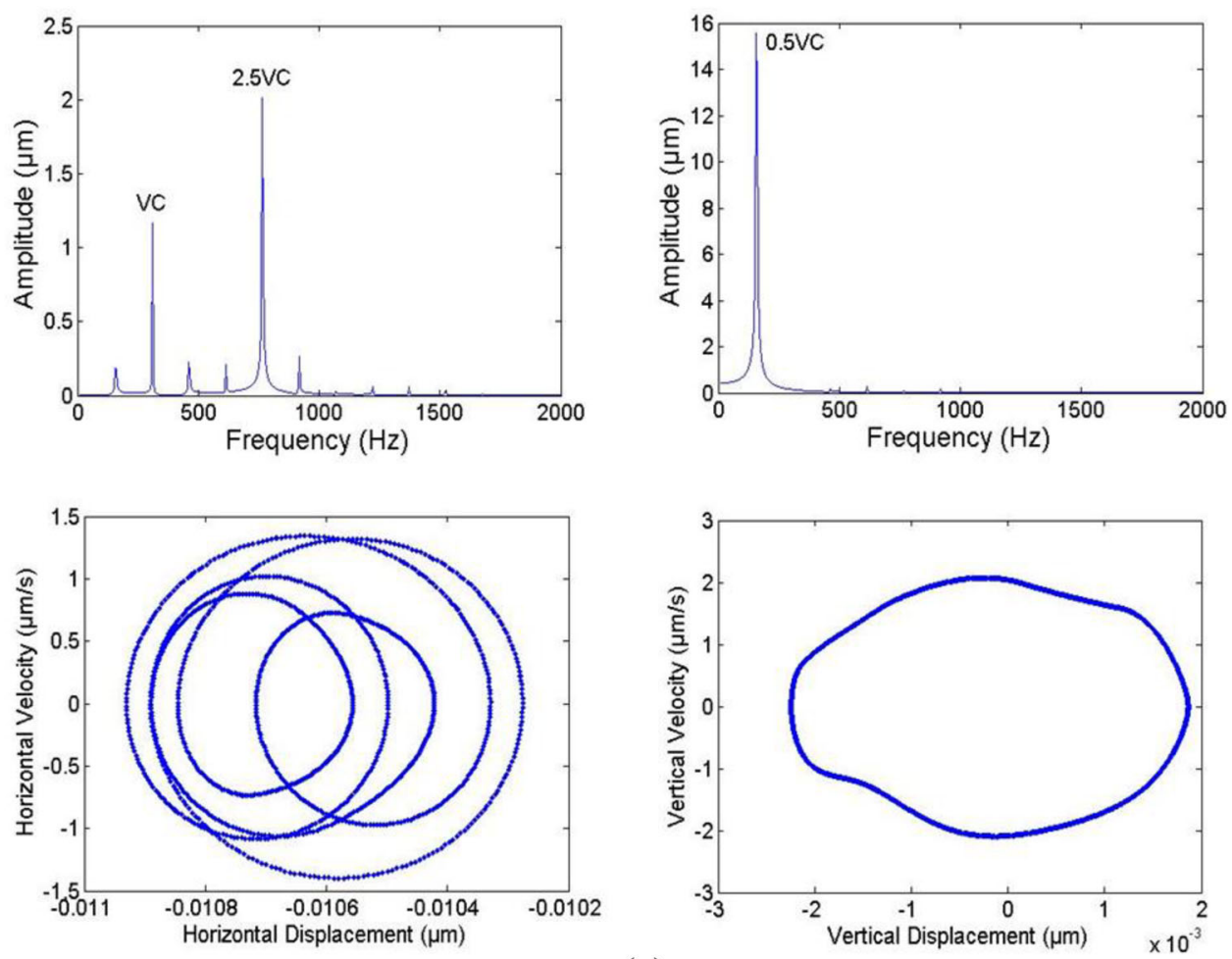

(e)
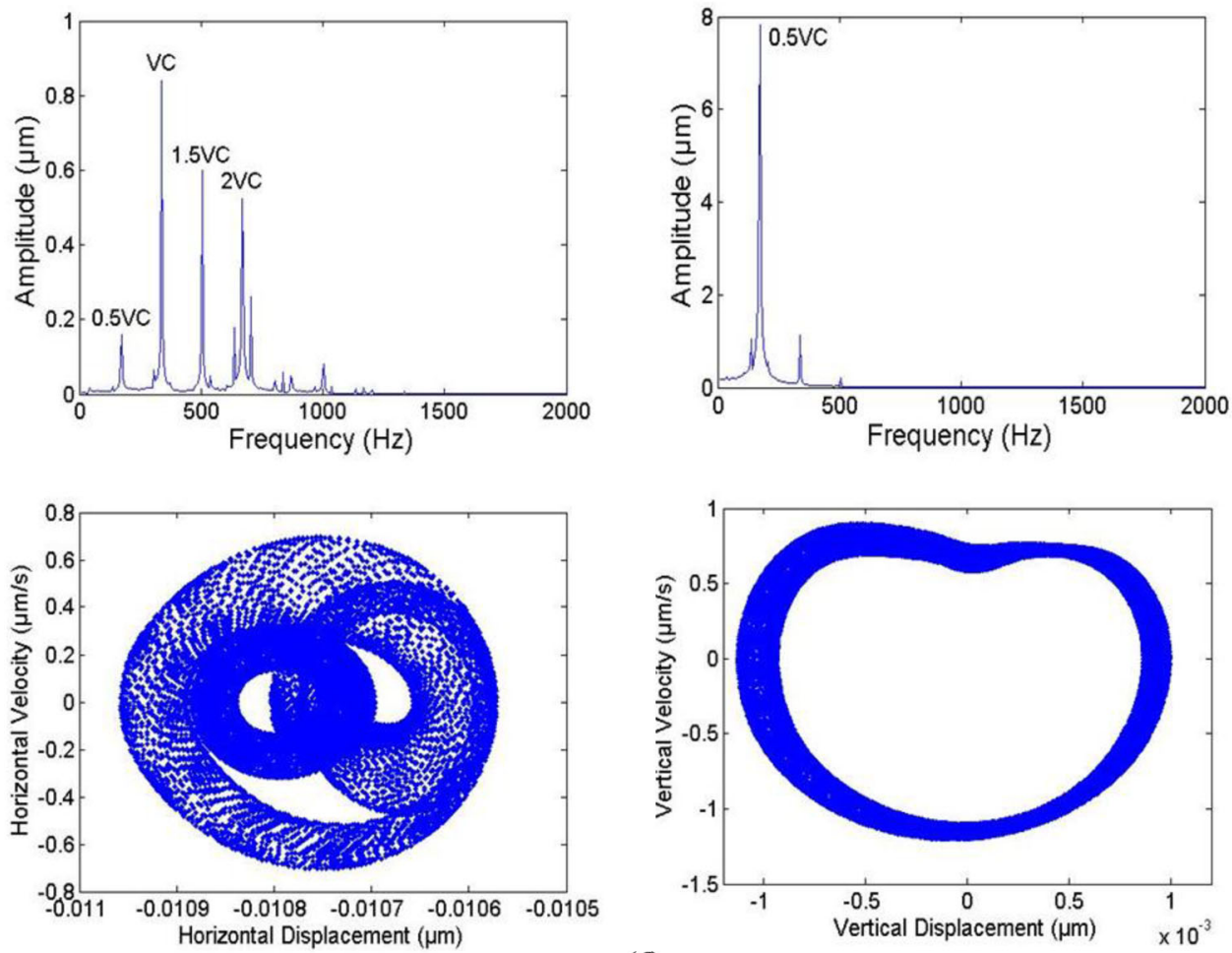

(f)

Figure 6. continued

unstable region is identified with further increment in speed to $8430 \mathrm{rpm}$. This region, $8430-9470 \mathrm{rpm}$, is identified as the fourth unstable region of the healthy rotor-bearing system.
This unstable region is due to the spread-out of the chaotic attractor and period-doubling bifurcation is prominent in the presence of the attractor. 

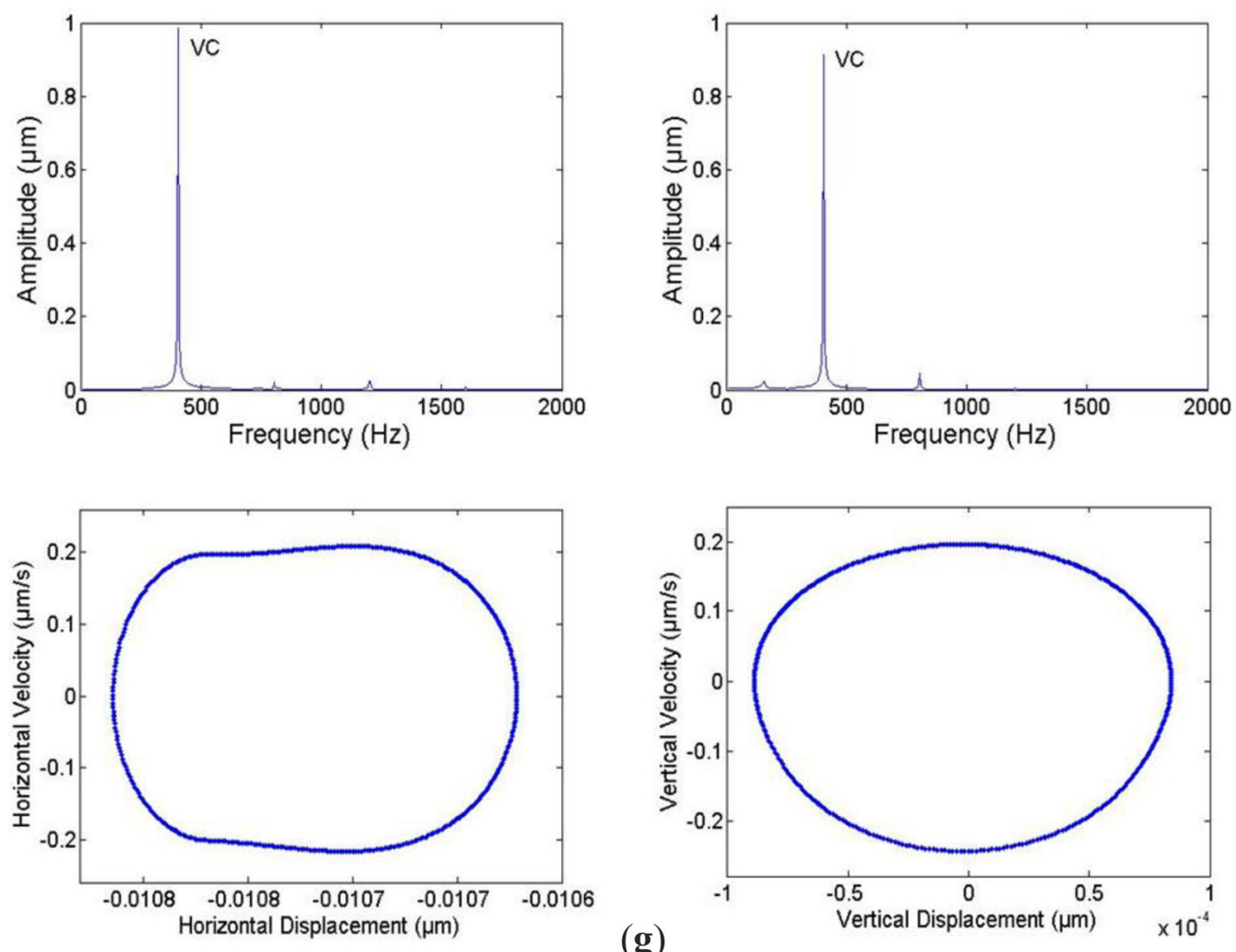

(g)
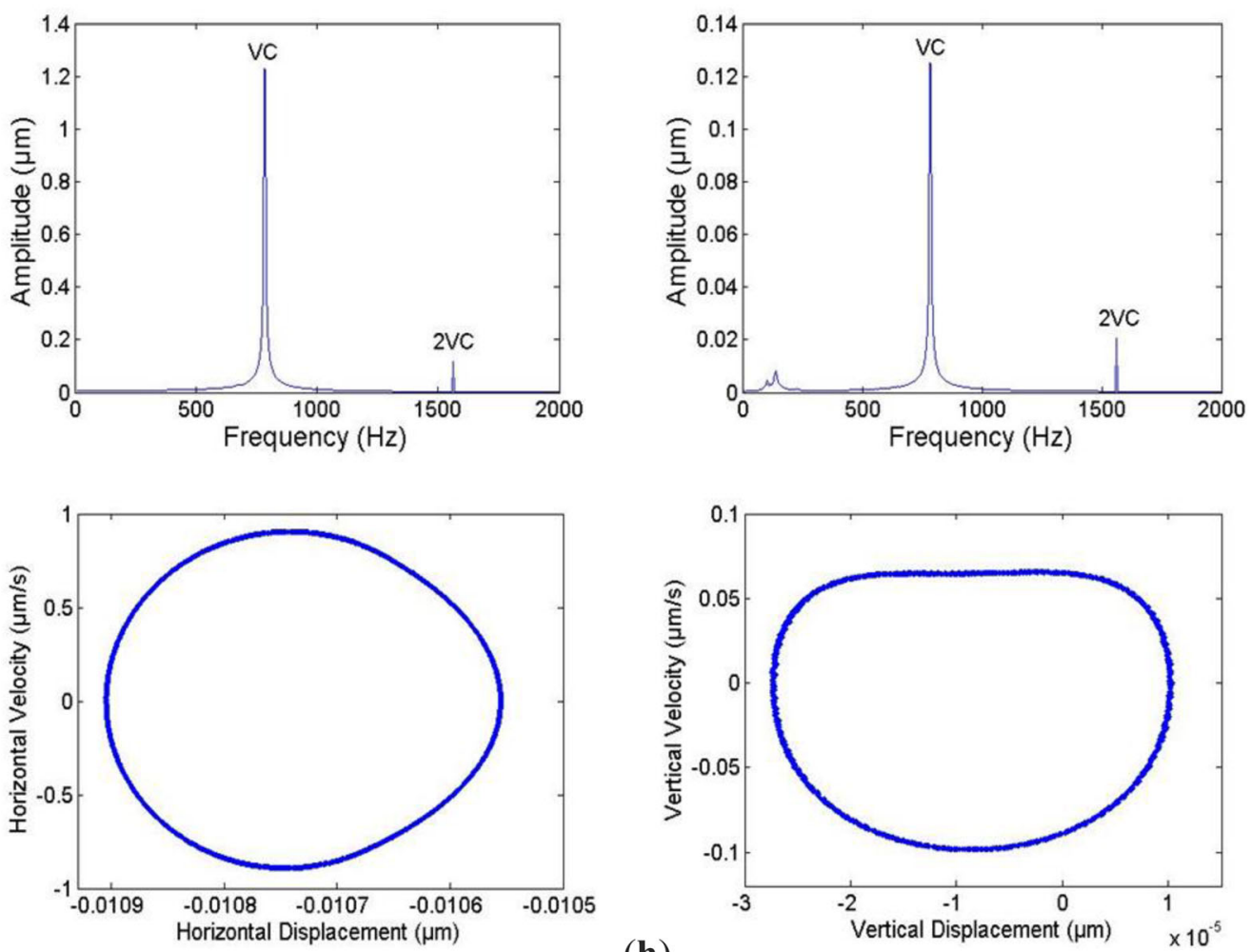

(h)

Figure 6. continued

The system regains its stability with further increment in speed from 9480 to $10000 \mathrm{rpm}$. Response plots in this region at $9500 \mathrm{rpm}$ are shown in figure $6 \mathrm{i}$ and the peak amplitudes in frequency spectrums are noticed at $V C(906.6 \mathrm{rad} / \mathrm{s})$ in both horizontal and vertical directions. The HFDs at $9500 \mathrm{rpm}$ are calculated as 1.0184 and 1.0258 , respectively, in horizontal 

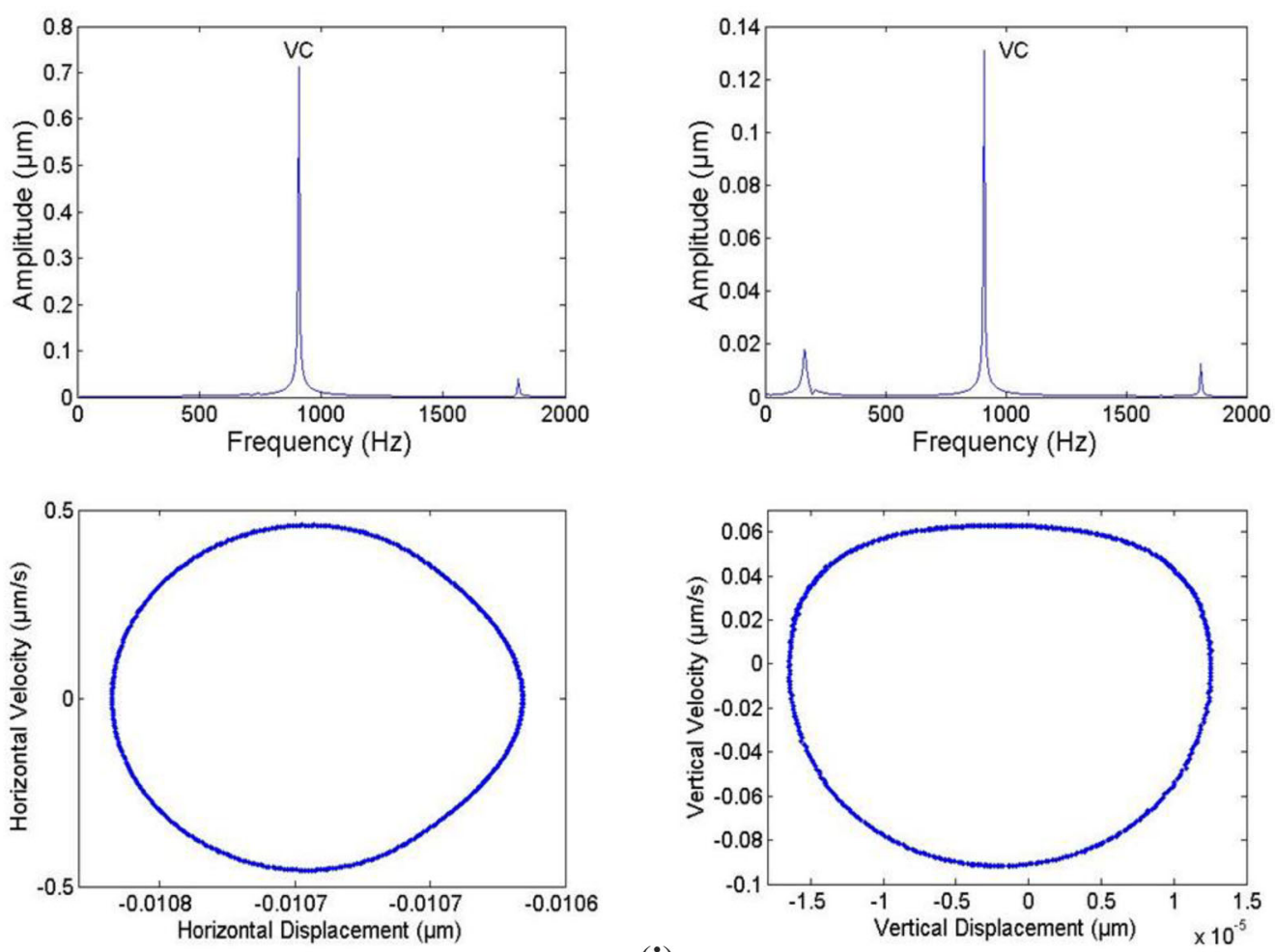

(i)
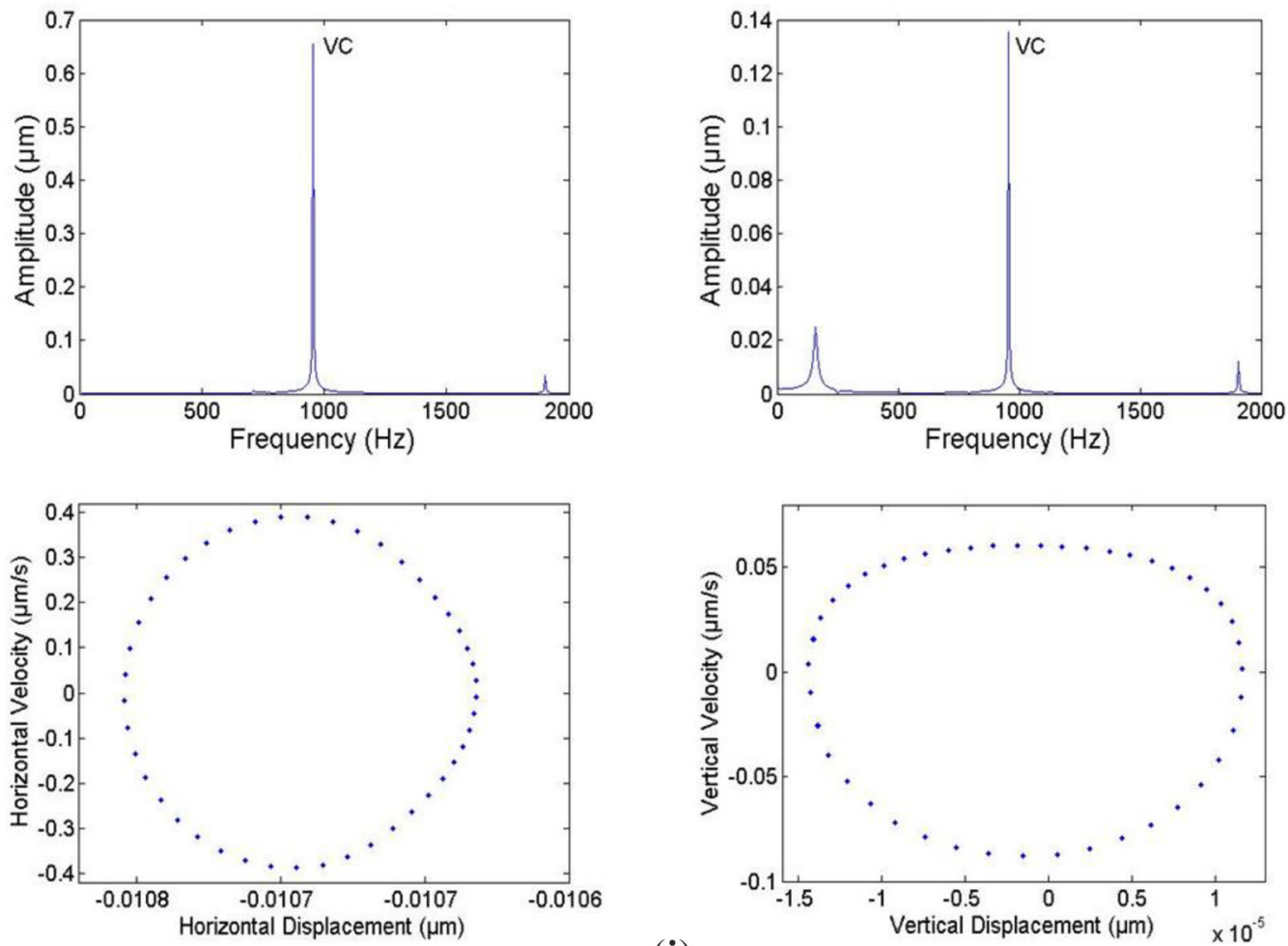

(j)

Figure 6. continued

and vertical directions. For $10000 \mathrm{rpm}$, the peak amplitudes can be noticed at $V C(954.5 \mathrm{rad} / \mathrm{s})$ in both horizontal and vertical directions, as indicated in figure $6 \mathrm{j}$. The closed orbit
Poincaré maps indicate the periodic nature of the system and HFDs are found to be 1.0650 and 1.0257 , respectively, in horizontal and vertical directions. 
Table 2. Summary of solutions of healthy bearing at various speeds.

\begin{tabular}{|c|c|c|c|c|c|}
\hline \multirow[b]{2}{*}{ Speed (rpm) } & \multirow[b]{2}{*}{ Nature of solution } & \multicolumn{2}{|c|}{ Peak amplitude at } & \multicolumn{2}{|c|}{ HFDs } \\
\hline & & Horizontal & Vertical & Horizontal & Vertica \\
\hline 800 & Multi-orbit periodic & $10 V C$ & $2 V C$ & 1.0379 & 1.0910 \\
\hline 1700 & Chaotic & $4.5 V C$ & $V C$ & 1.7552 & 1.7619 \\
\hline 2480 & Multi-orbit periodic & $3 V C$ & $0.5 V C$ & 1.0166 & 1.0271 \\
\hline 2590 & Chaotic & $3 V C$ & $0.5 V C$ & 1.7351 & 1.7233 \\
\hline 3200 & Multi-orbit periodic & $2.5 \mathrm{VC}$ & $0.5 V C$ & 1.0937 & 1.0940 \\
\hline 3500 & Quasi-periodic & $V C$ & $0.5 V C$ & 1.4900 & 1.5821 \\
\hline 4200 & Periodic & $V C$ & $V C$ & 1.0168 & 1.0142 \\
\hline 8200 & Quasi-periodic & $V C$ & $V C$ & 1.0373 & 1.3787 \\
\hline 9500 & Periodic & $V C$ & $V C$ & 1.0184 & 1.0258 \\
\hline 10000 & Periodic & $V C$ & $V C$ & 1.0650 & 1.0257 \\
\hline
\end{tabular}

For the healthy rotor-bearing system, the vibration responses are found to be associated with varying compliance frequency and its harmonics. The detailed nature of solutions, the value of peak amplitudes and HFDs are summarized in table 2. The overall response of healthy cylindrical roller bearing is shown in figure 7 . The overall response shows a very rough appearance with high amplitudes of vertical vibrations and four unstable regions indicated, bounded by $\mathrm{A}-\mathrm{A}^{\prime}, \mathrm{B}-\mathrm{B}^{\prime}, \mathrm{C}-\mathrm{C}^{\prime}$ and $\mathrm{D}-\mathrm{D}^{\prime}$.

The response plots of roller bearing having spalled inner race are shown in figure 8 . The rotor-bearing system exhibits chaotic behaviour up to $1180 \mathrm{rpm}$. The response of the system at $1180 \mathrm{rpm}$ is shown in figure $8 \mathrm{a}$, where the peak amplitude of vibration appears in terms of wave passage frequency $\left(\omega_{w p}\right)$ at $\omega_{w p}(168.2 \mathrm{rad} / \mathrm{s})$ and $0.5 \omega_{w p}$ (86.36 rad/s), respectively, in horizontal and vertical vibration directions and other major peaks appear at $2 \omega_{w p}$ (331.8 rad/s) and $4 \omega_{w p}(659.1 \mathrm{rad} / \mathrm{s})$ in horizontal direction. The HFDs are employed to quantify the nonlinearity of this system and obtained as 1.9245 and 1.8922, respectively, in horizontal and vertical directions. As the speed is further increased, the system comes out of the chaotic region. The Poincaré maps show the periodic nature of the system from 1200 to $1710 \mathrm{rpm}$. Response plots in this stable region at $1710 \mathrm{rpm}$ are shown in figure $8 \mathrm{~b}$, where peak amplitude can be noticed at $\omega_{w p}(240.9 \mathrm{rad} / \mathrm{s})$ in both horizontal and vertical directions. The HFDs of the system at $1710 \mathrm{rpm}$ are obtained as 1.0595 and 1.0717, respectively, in horizontal and vertical directions.

The system again enters the chaotic region with an increase in speed from 1720 to $1810 \mathrm{rpm}$. The response plots in this chaotic region at $1810 \mathrm{rpm}$ are shown in figure $8 \mathrm{c}$, where the peak amplitudes of vibration appear at $0.5 \omega_{w p}+2 X(172.7 \mathrm{rad} / \mathrm{s})$ and at $3 X \quad(86.36 \mathrm{rad} / \mathrm{s})$, respectively, in horizontal and vertical directions, where $X$ is rotation frequency of shaft, and other major peaks appear at $2 \omega_{w p}+3 X(586.3 \mathrm{rad} / \mathrm{s}), 1.5 \omega_{w p}+2 X(422.7 \mathrm{rad} / \mathrm{s})$ and $2 \omega_{w p}(504.5 \mathrm{rad} / \mathrm{s})$ in horizontal direction. The HFDs of the system at $1810 \mathrm{rpm}$ are found to be 1.9067 and 1.9031 , respectively, in horizontal and vertical directions. Also, the Poincaré maps show the chaotic nature of the system at this speed. This region, $1720-1810 \mathrm{rpm}$, is identified as the second unstable region. The system regains its stability with further increment in speed to $1840 \mathrm{rpm}$ and remains

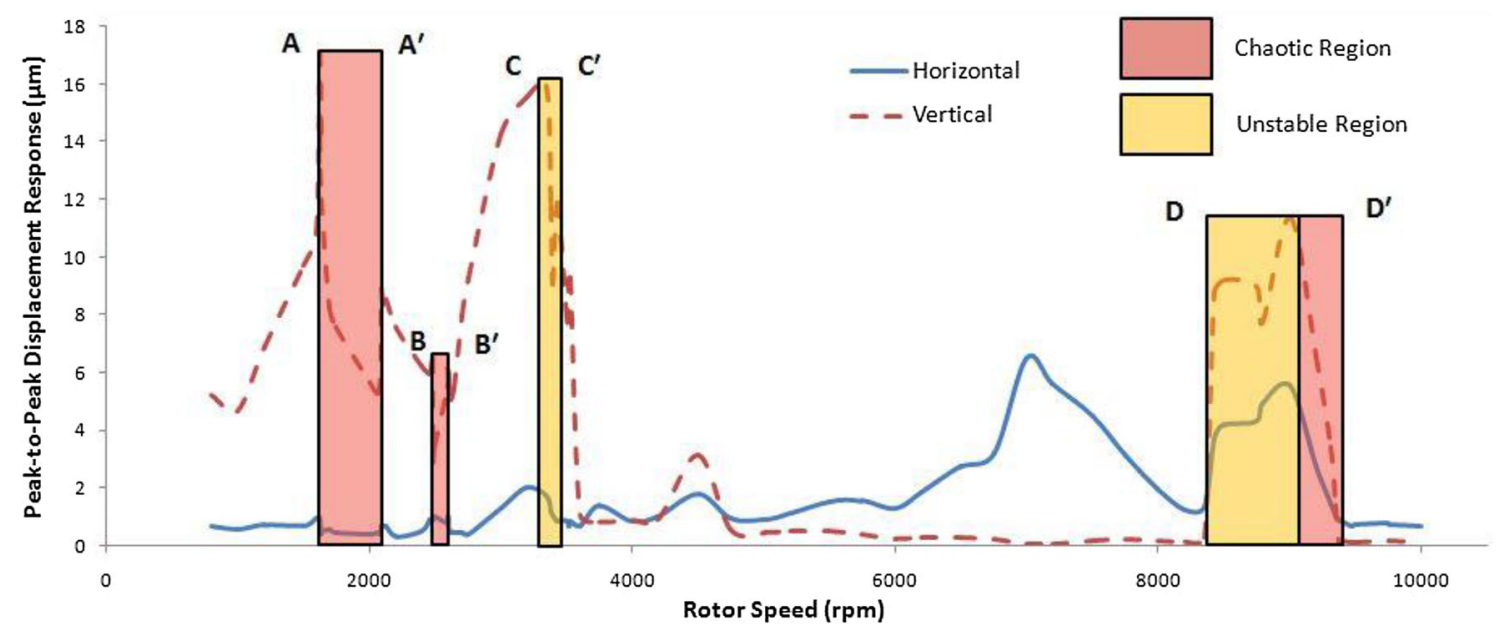

Figure 7. Overall response plot for the healthy bearing. 

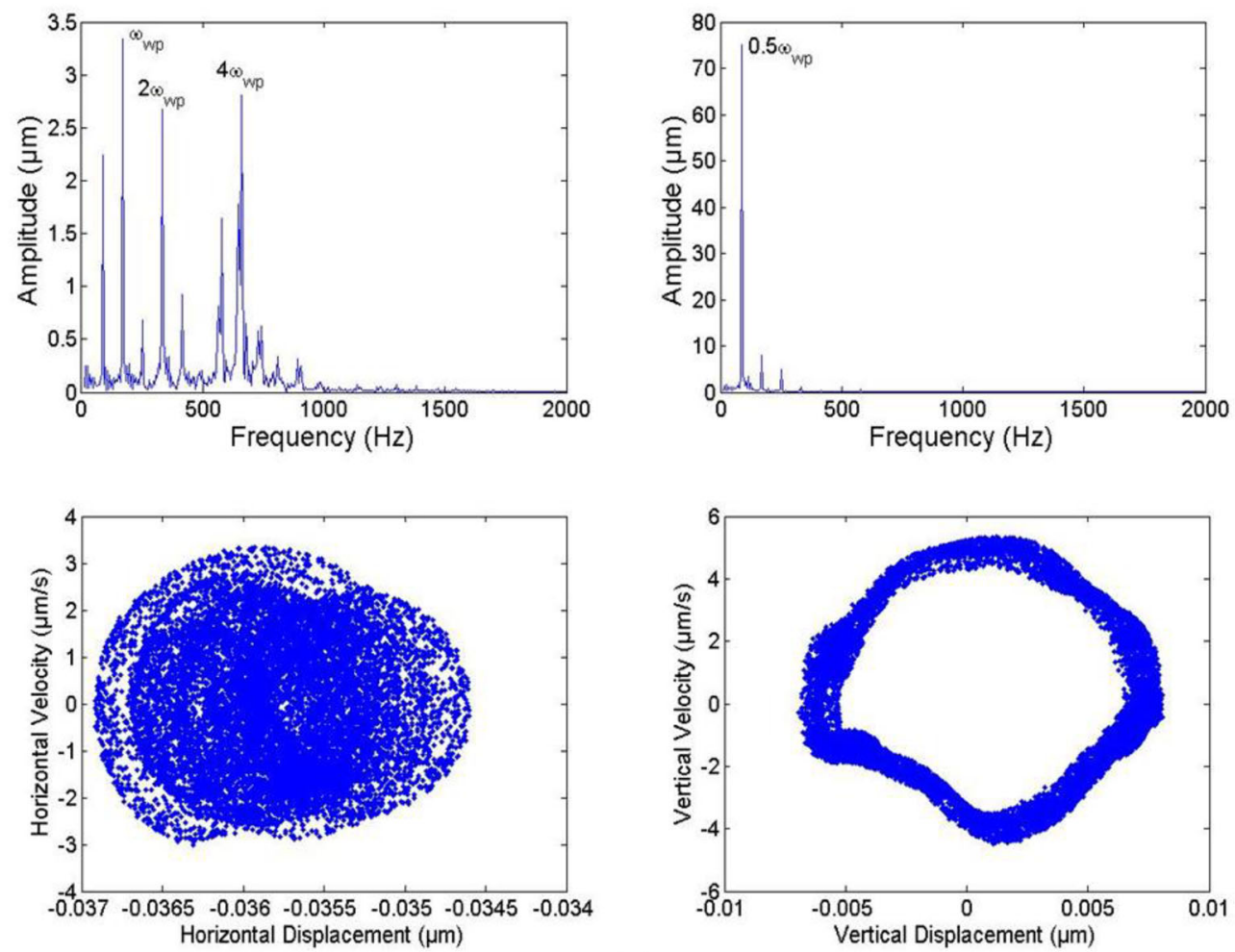

(a)
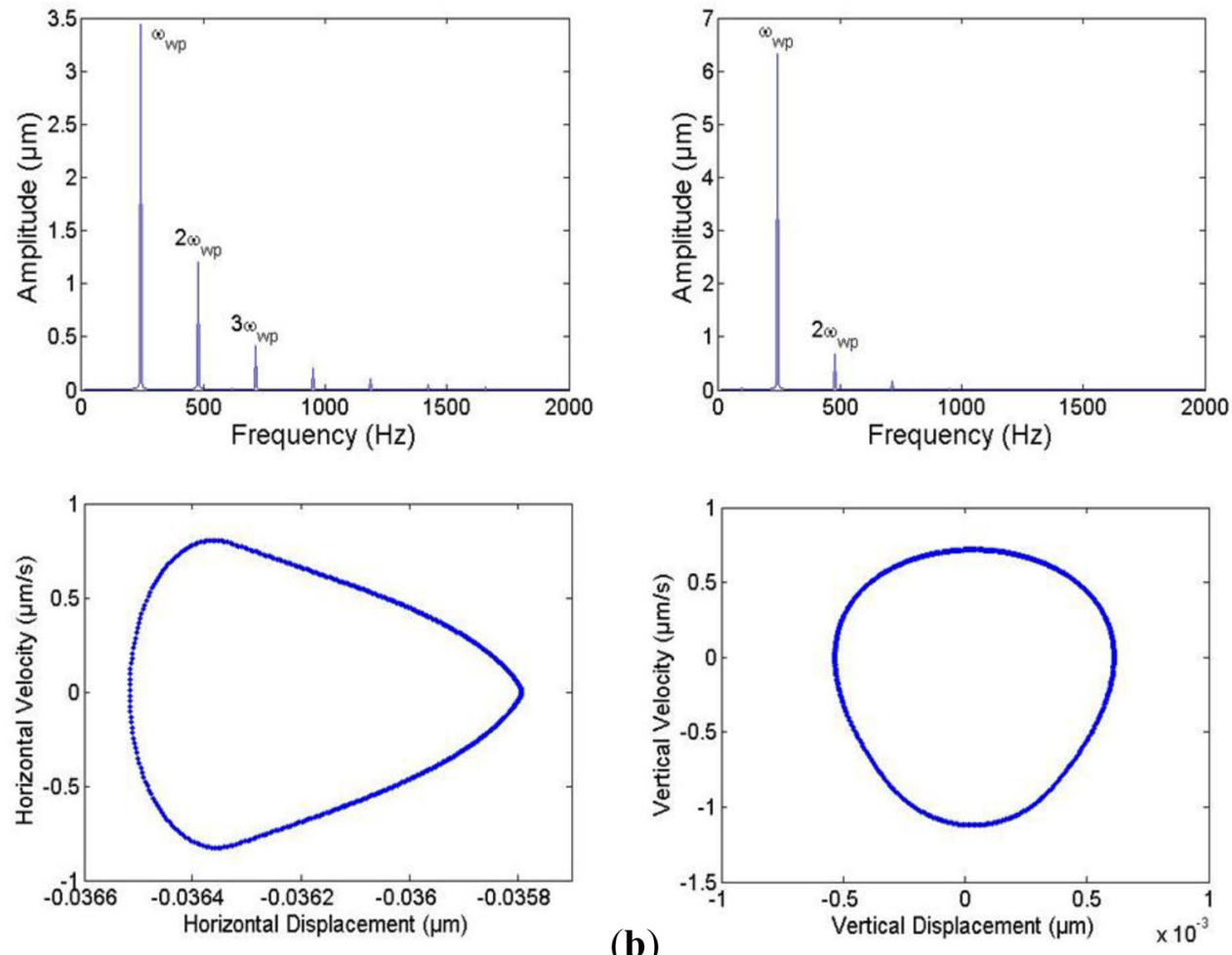

(b)

Figure 8. Response plots of bearing having inner race defect at (a) $1180 \mathrm{rpm}$, (b) $1710 \mathrm{rpm}$, (c) $1810 \mathrm{rpm}$, (d) $2185 \mathrm{rpm}$, (e) $2200 \mathrm{rpm}$, (f) $2575 \mathrm{rpm}$, (g) $3200 \mathrm{rpm}$, (h) $4000 \mathrm{rpm}$, (i) $4630 \mathrm{rpm}$, (j) $5200 \mathrm{rpm}$, (k) $6235 \mathrm{rpm}$ and (l) $9200 \mathrm{rpm}$. 

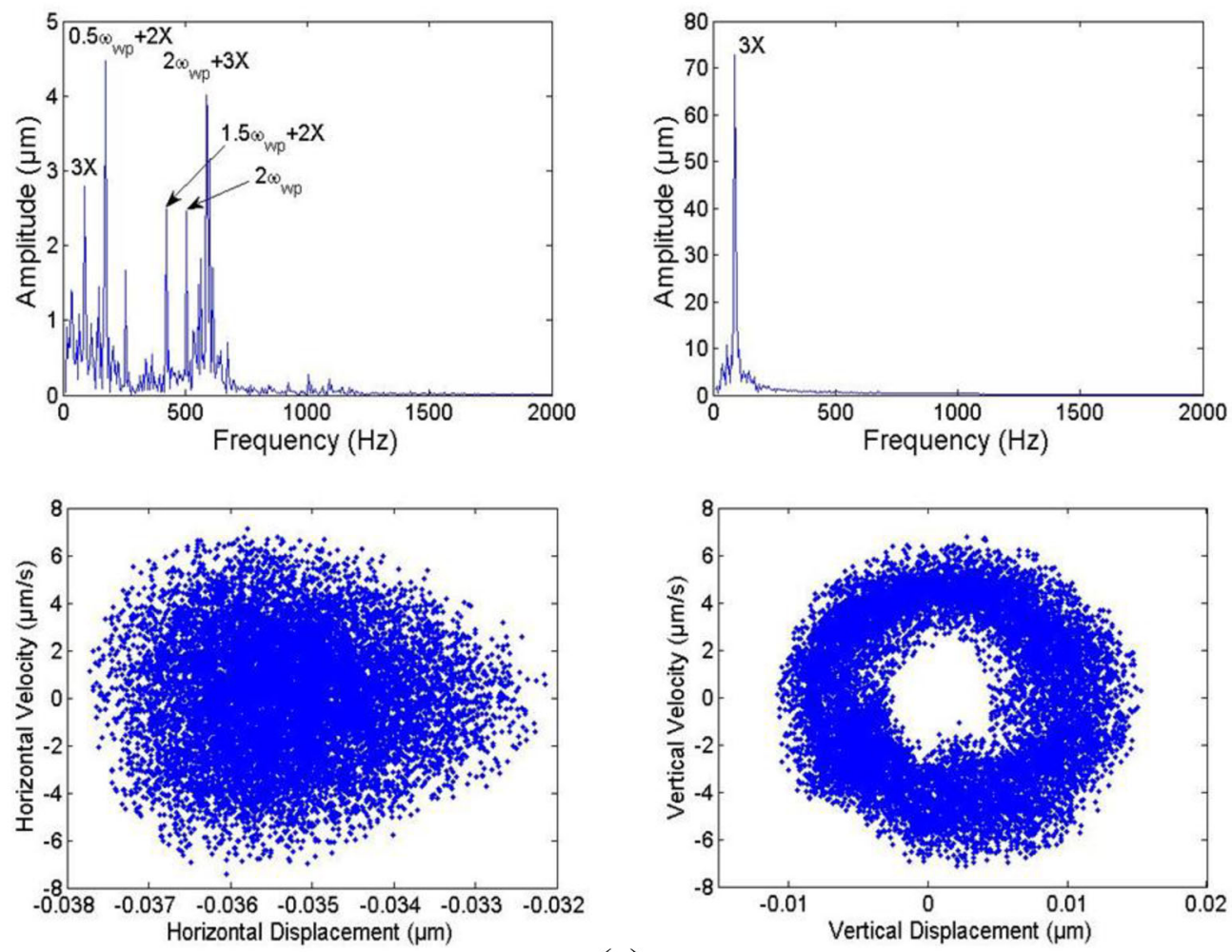

(c)
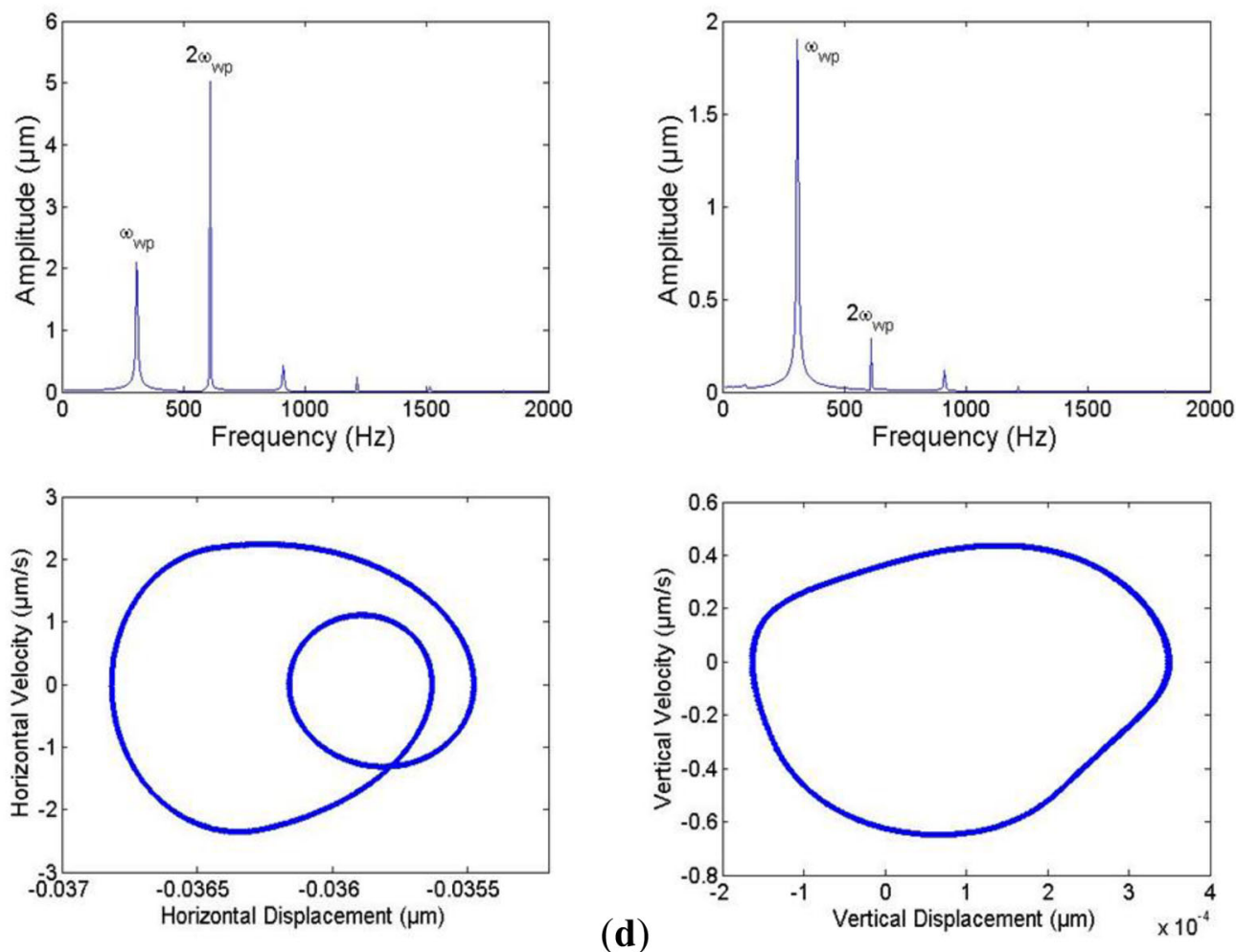

Figure 8. continued

stable up to $2185 \mathrm{rpm}$. Response plots of the system at $2185 \mathrm{rpm}$ in this region are shown in figure $8 \mathrm{~d}$, where peak amplitudes are found at $2 \omega_{w p}(609.1 \mathrm{rad} / \mathrm{s})$ and $\omega_{w p}$
(304.5 rad/s), respectively, for horizontal and vertical responses. The HFDs are obtained as 1.0960 and 1.0926, respectively, in horizontal and vertical directions and the 

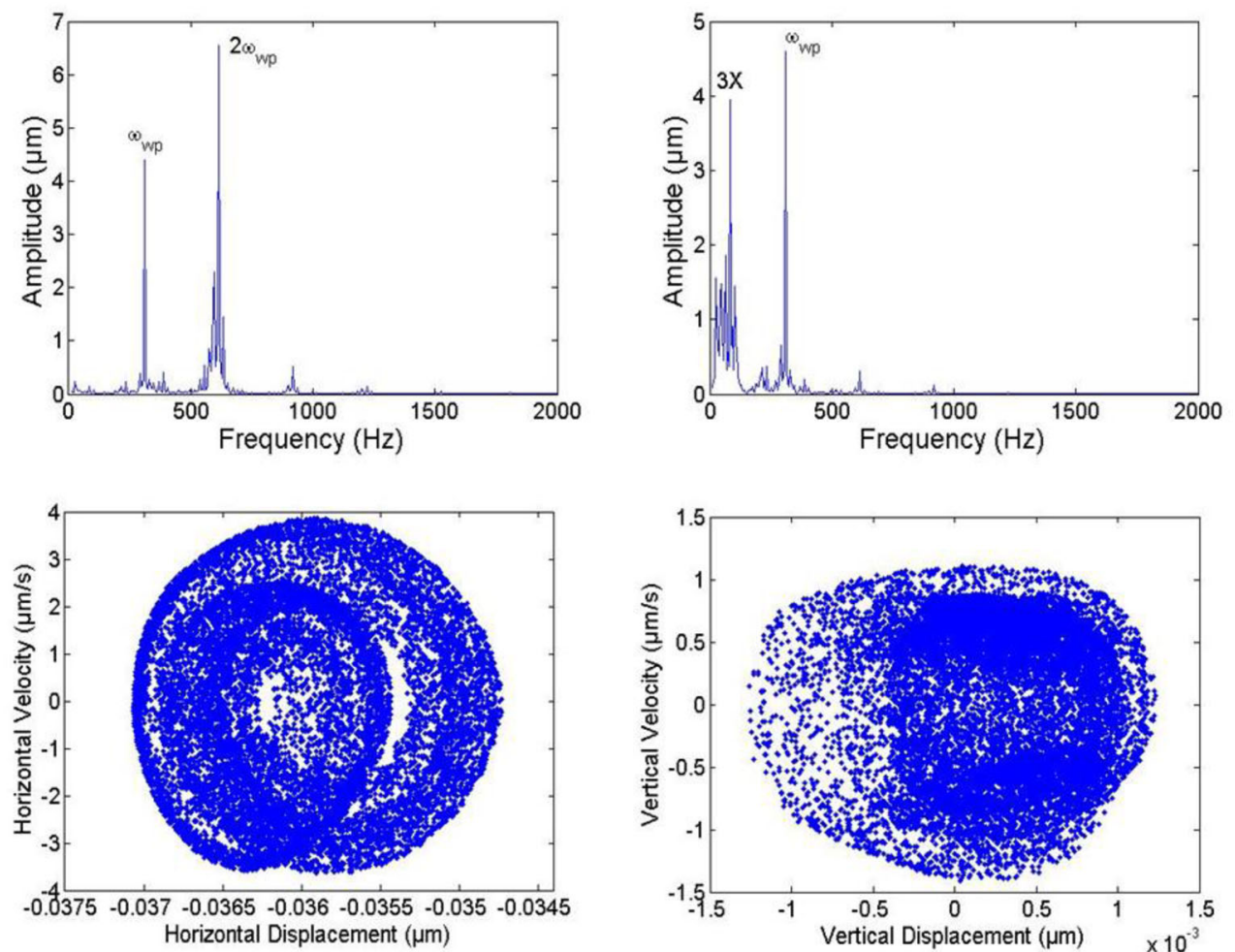

(e)
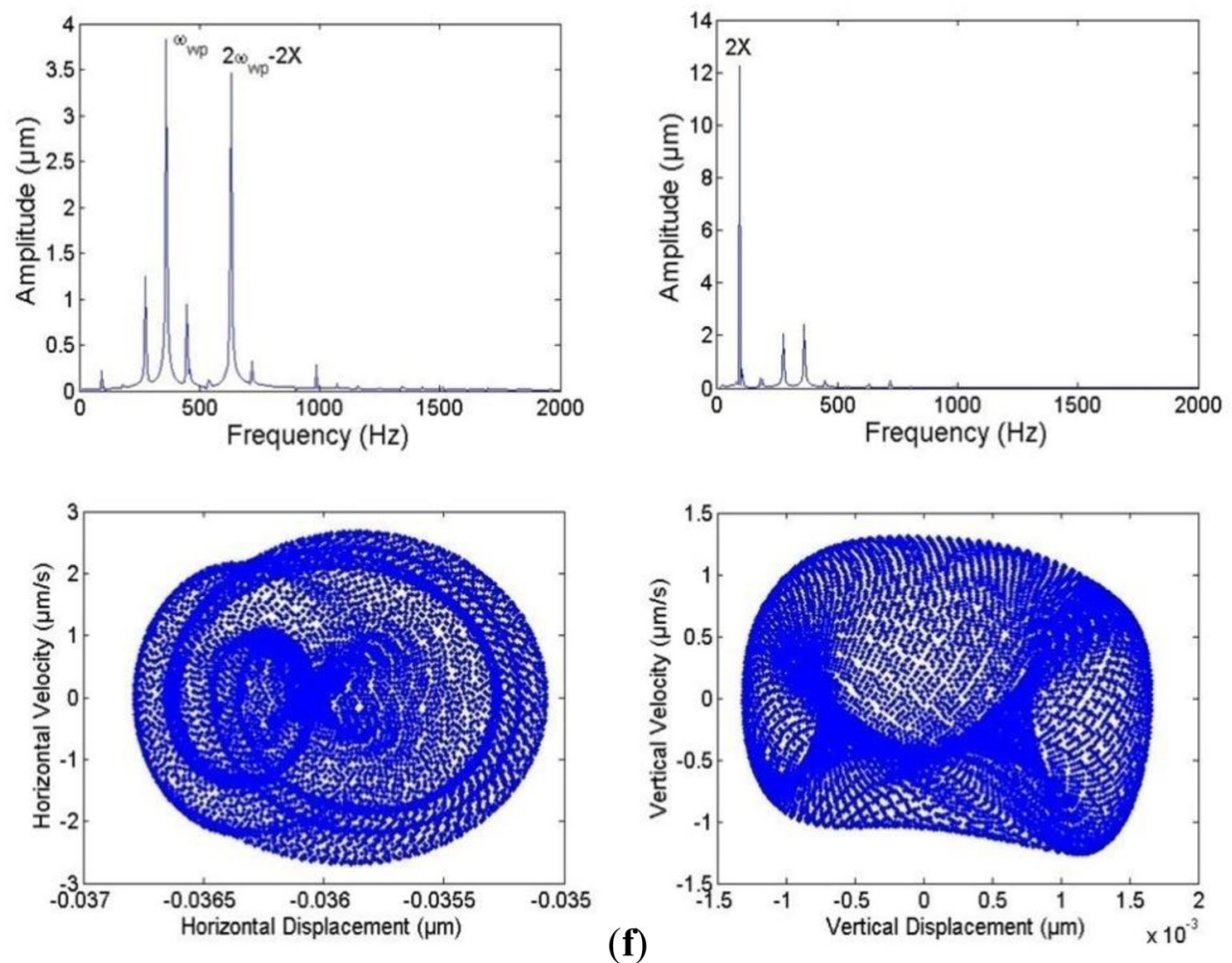

Figure 8. continued

Poincare maps show the periodic nature of the system. The third unstable region is observed with further increment in speed to $2200 \mathrm{rpm}$, and remains up to $2575 \mathrm{rpm}$. The system shows the chaotic response in this region due to the spread-out of chaotic attractor. In this unstable region, the peak amplitude of vibration at $2200 \mathrm{rpm}$ is observed at $2 \omega_{w p}$ 

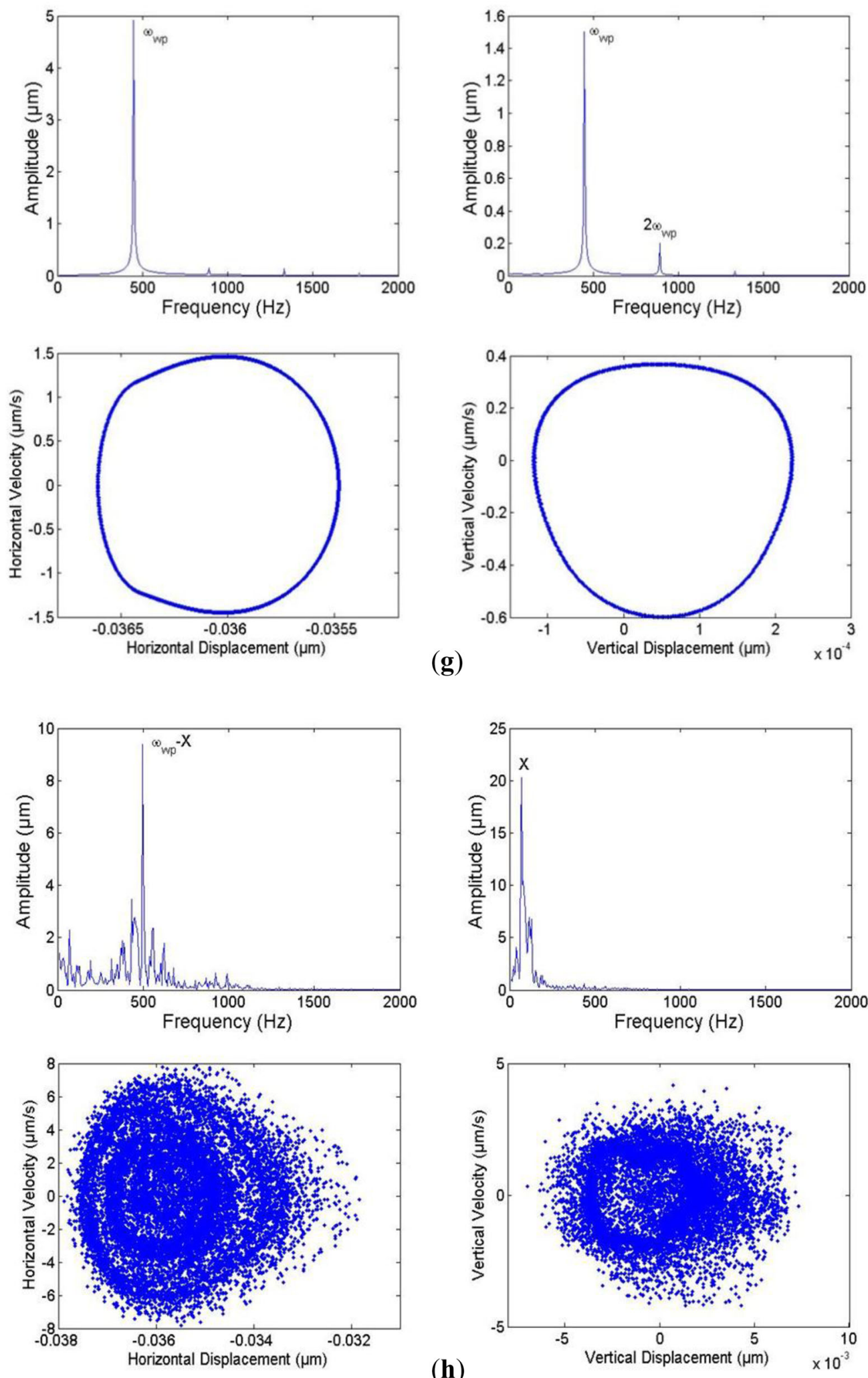

(h)

Figure 8. continued

$(613.6 \mathrm{rad} / \mathrm{s})$ and $\omega_{w p}(309.1 \mathrm{rad} / \mathrm{s})$, as indicated in figure 8e. The HFDs for this speed are also obtained as 1.7302 and 1.7494, respectively, in horizontal and vertical directions. The system exhibits quasi-periodic behaviour at $2575 \mathrm{rpm}$, where peaks can be noticed at $\omega_{w p}(359.1 \mathrm{rad} / \mathrm{s})$ and $2 X(90.9 \mathrm{rad} / \mathrm{s})$, respectively, for horizontal and vertical 

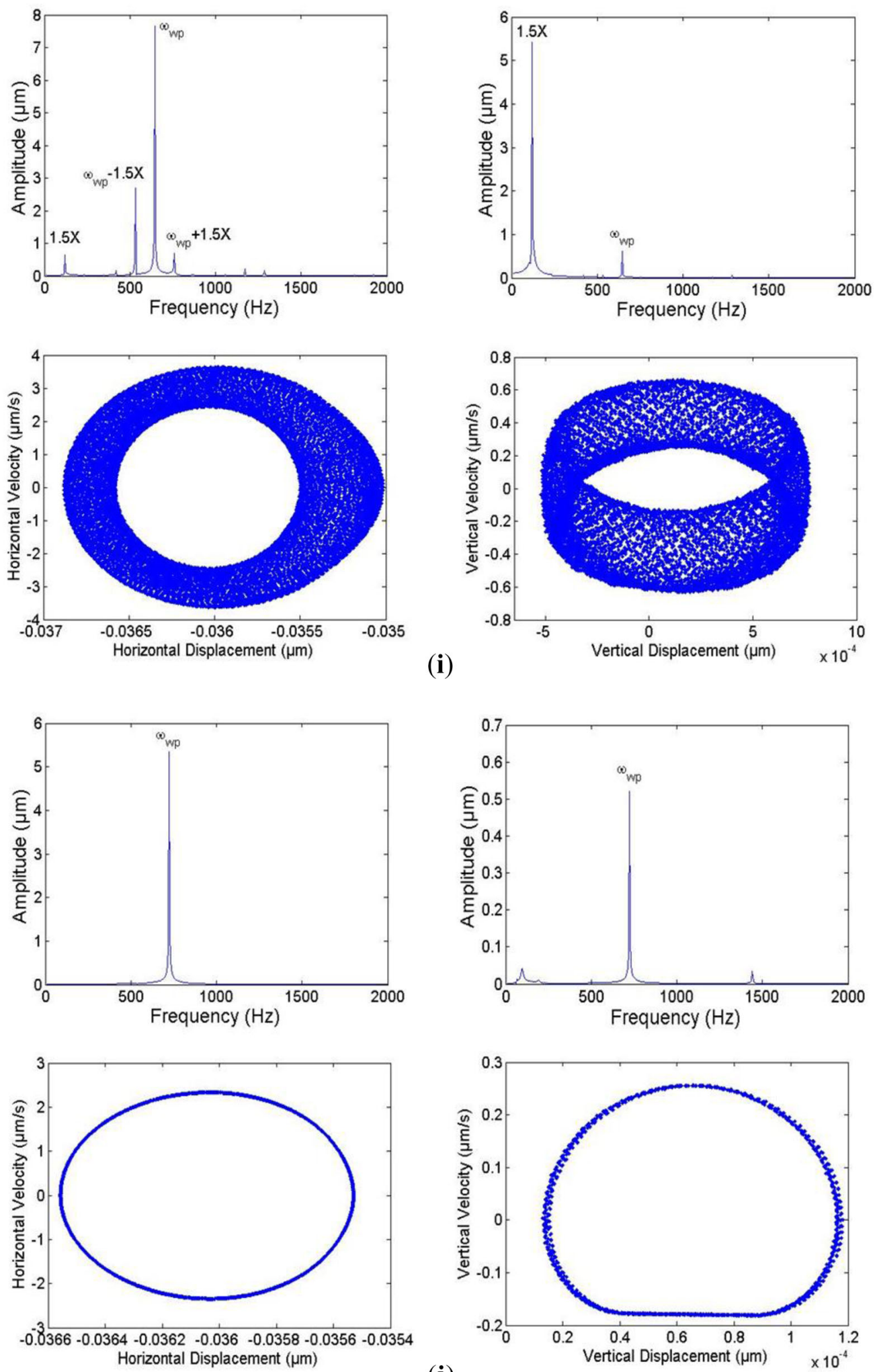

(j)

Figure 8. continued

responses as shown in figure 8f. The HFDs are found to be 1.6259 and 1.5890 at $2575 \mathrm{rpm}$, respectively, in horizontal and vertical directions.
The system achieves stability with further increment in speed to $2600 \mathrm{rpm}$ and remains stable up to $3800 \mathrm{rpm}$. Response plots in this stable region of the rotor-bearing 

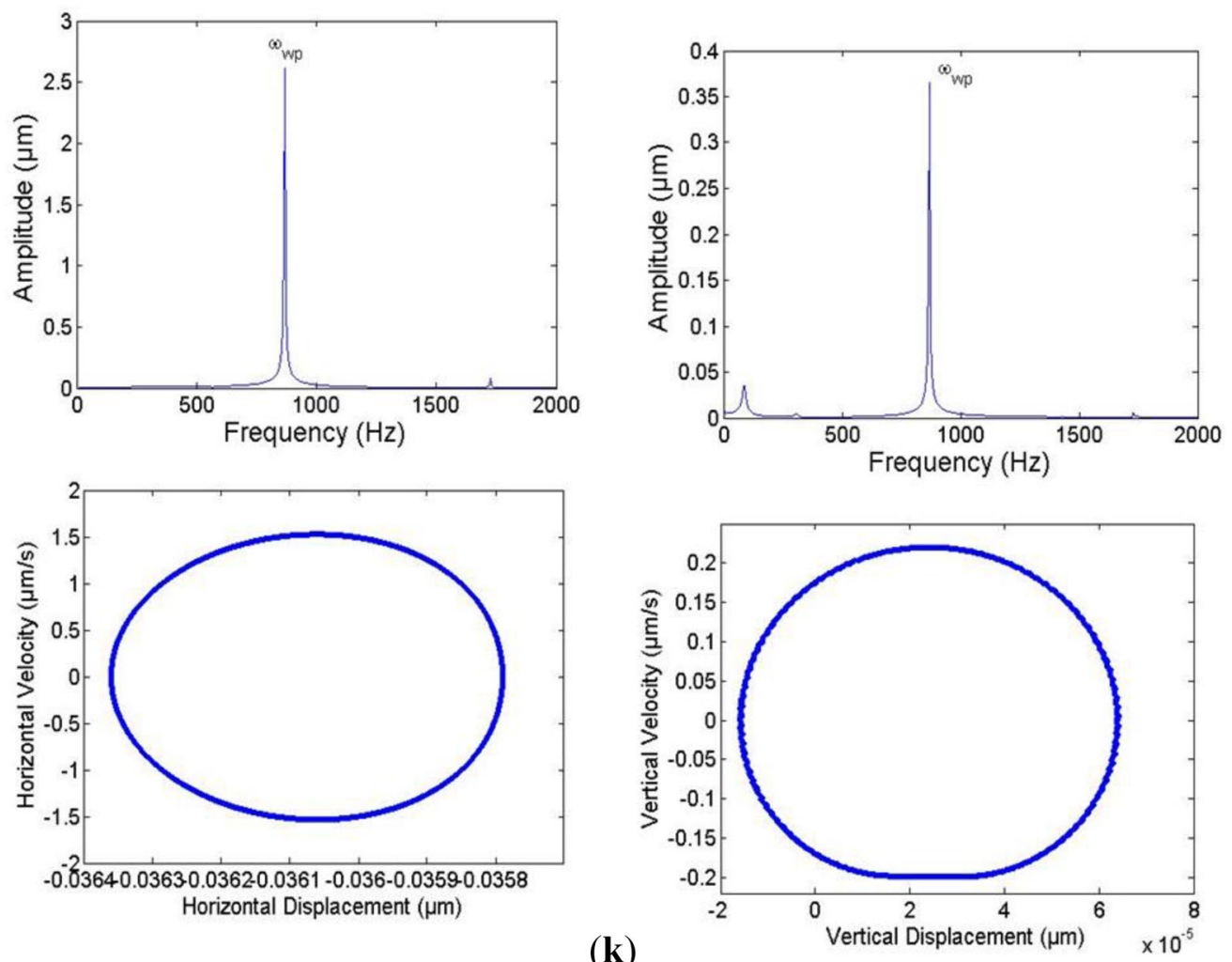

(k)
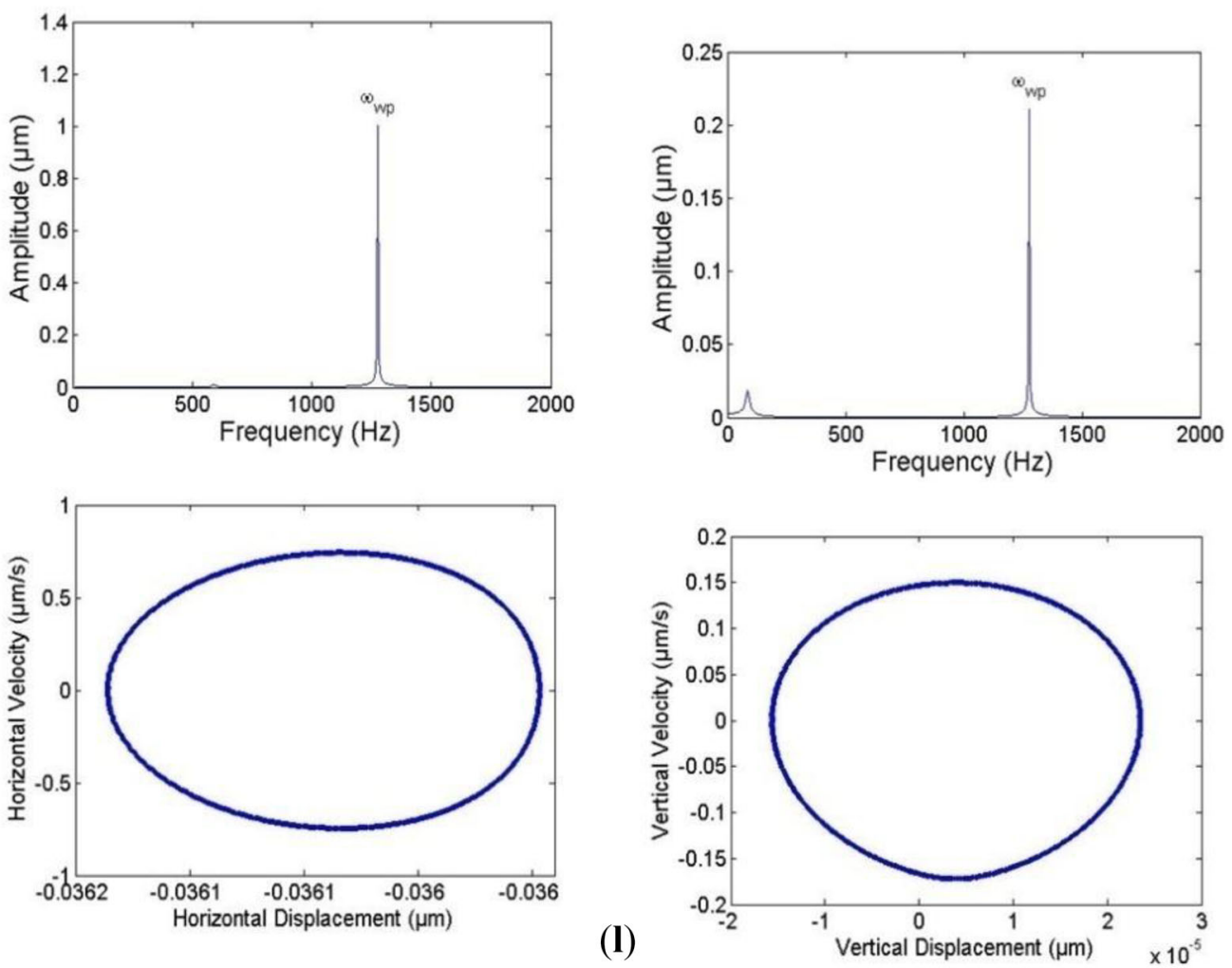

Figure 8. continued

system at $3200 \mathrm{rpm}$ are shown in figure $8 \mathrm{~g}$, where the peak amplitude is observed at $\omega_{w p}(445.4 \mathrm{rad} / \mathrm{s})$ in both horizontal and vertical directions. Moreover, the nonlinearity of the system is quantified as 1.0295 and 1.0185 in horizontal and vertical directions, respectively, which shows the stable nature of the system. The rotor-bearing system loses 
its stability again for the speed ranging from 3840 to $6255 \mathrm{rpm}$ due to eigenvalue crossing +1 . Response plots stable at 4000, 4630, 5200 and $6235 \mathrm{rpm}$ are shown in figure $8 \mathrm{~h}, \mathrm{i}, \mathrm{j}$ and $\mathrm{k}$, respectively. The Poincaré maps confirm the chaotic response from 3980 to $4500 \mathrm{rpm}$; further, the system shows quasiperiodic response up to $4630 \mathrm{rpm}$. The peak amplitudes of vibration at $4630 \mathrm{rpm}$ are found at $\omega_{w p}(640.9 \mathrm{rad} / \mathrm{s})$ and at $1.5 X(118.2 \mathrm{rad} / \mathrm{s})$, respectively, for horizontal and vertical responses, as shown in figure 8i. The HFDs for these speeds are estimated as 1.8223 and 1.8389 for $4000 \mathrm{rpm}, 1.5608$ and 1.5118 for $4630 \mathrm{rpm}$, 1.0886 and 1.0492 for $5200 \mathrm{rpm}$ and 1.0844 and 1.0391 for $6235 \mathrm{rpm}$, respectively, in horizontal and vertical directions. The close orbit shaped Poincaré maps of higher speed, from 6265 to $10000 \mathrm{rpm}$, show periodic nature of the system. Response plots in this stable region at $9200 \mathrm{rpm}$ are shown in figure 81, where the peak amplitude can be noticed at $\omega_{w p}(1277 \mathrm{rad} / \mathrm{s})$ and HFDs are obtained as 1.0166 and 1.0197, respectively, in horizontal and vertical directions.

In the presence of defect on inner race, the peak-to-peak amplitude of vibration increases significantly. The nature of solutions at various speeds, the value of peak amplitudes and HFDs of the system having outer race defect are summarized in table 3 . The overall response plot for the system having an inner race defect is shown in figure 9. It shows very rough appearance and four unstable regions are shown as $\mathrm{A}-\mathrm{A}^{\prime}, \mathrm{B}-\mathrm{B}^{\prime}, \mathrm{C}-\mathrm{C}^{\prime}$ and $\mathrm{D}-\mathrm{D}^{\prime}$.

The responses of the system having an outer race defect are shown in figure 10. The rotor-bearing system shows unstable nature up to $1938 \mathrm{rpm}$. Response plots of the system in this unstable region at $1900 \mathrm{rpm}$ are shown in figure 10a, where the peak amplitude of vibration is observed in terms of ball passage frequency $\left(\omega_{b p}\right)$ at $0.5 \omega_{b p}$ (95.45 rad/s) in both horizontal and vertical directions. The fractal structure of the Poincare maps indicates the chaotic nature of the system and the HFDs are obtained as 1.7849 and 1.7795, respectively, in horizontal and vertical directions. The system regains its stability with further increment in speed from $1960 \mathrm{rpm}$, and remains stable up to $2405 \mathrm{rpm}$. Responses in this region at $2200 \mathrm{rpm}$ are shown in figure $10 \mathrm{~b}$, where the peak amplitude is perceived at $\omega_{b p}$ (213.6 rad/s) in both horizontal and vertical directions and other major peaks are observed at $2 \omega_{b p}(422.7 \mathrm{rad} / \mathrm{s}), 3 \omega_{b p}$ $(631.8 \mathrm{rad} / \mathrm{s})$ and $4 \omega_{b p}(846.3 \mathrm{rad} / \mathrm{s})$ in horizontal direction and at $3 X(109.6 \mathrm{rad} / \mathrm{s})$ and $2 \omega_{b p}(423.9 \mathrm{rad} / \mathrm{s})$ in vertical direction. At $2200 \mathrm{rpm}$, the Poincare maps show the periodic nature of the system and the HFDs are calculated as 1.0254 and 1.0269, respectively, in horizontal and vertical directions.

Another unstable region is identified when the rotor speed is increased beyond $2425 \mathrm{rpm}$. The system shows unstable nature up to $2645 \mathrm{rpm}$. This region is identified as the second unstable region of the bearing in the presence of defective rolling element. In this region, the system loses its stability due to the sudden attack of chaotic attractor. Response plots of the system in this unstable region at rotor speed $2615 \mathrm{rpm}$ are shown in figure 10c, where the peak amplitudes of vibration appear at shaft rotational frequency of $0.5 \omega_{b p}+X(168.2 \mathrm{rad} / \mathrm{s})$, where $X$ is due to the interaction effect of ball passage frequency and shaft rotational frequency, and at its super-harmonic $2 X(86.36 \mathrm{rad} / \mathrm{s})$, respectively, in horizontal and vertical directions. The other major peaks are perceived at $2 \omega_{b p}(500 \mathrm{rad} / \mathrm{s}), 2 \omega_{b p}$ $+X(550 \mathrm{rad} / \mathrm{s})$ and $2 X(86.25 \mathrm{rad} / \mathrm{s})$ in horizontal direction. The HFDs are employed to quantify the nonlinearity of the system and estimated as 1.9273 and 1.9085, respectively, in horizontal and vertical directions.

As the speed is further increased, the system regains its stability. This stable region starts at $2680 \mathrm{rpm}$, and remains up to $3196 \mathrm{rpm}$. Response plots in this region at $3196 \mathrm{rpm}$ are shown in figure $10 \mathrm{~d}$, where the peaks in frequency spectrums are found at harmonics of ball passage frequency $2 \omega_{b p}(613.6 \mathrm{rad} / \mathrm{s})$ and $\omega_{b p}(309.1 \mathrm{rad} / \mathrm{s})$, respectively, in

Table 3. Summary of solutions of bearing having an inner race defect at various speeds.

\begin{tabular}{|c|c|c|c|c|c|}
\hline \multirow[b]{2}{*}{ Speed (rpm) } & \multirow[b]{2}{*}{ Nature of solution } & \multicolumn{2}{|c|}{ Peak amplitude at } & \multicolumn{2}{|c|}{ HFDs } \\
\hline & & Horizontal & Vertical & Horizontal & Vertical \\
\hline 1180 & Chaotic & $\omega_{w p}$ & $0.5 \omega_{w p}$ & 1.9245 & 1.8922 \\
\hline 1710 & Periodic & $\omega_{w p}$ & $\omega_{w p}$ & 1.0595 & 1.0717 \\
\hline 1810 & Chaotic & $0.5 \omega_{w p}+2 X$ & $3 X$ & 1.9067 & 1.9031 \\
\hline 2185 & Periodic & $2 \omega_{w p}$ & $\omega_{w p}$ & 1.0960 & 1.0926 \\
\hline 2200 & Chaotic & $2 \omega_{w p}$ & $\omega_{w p}$ & 1.7302 & 1.7494 \\
\hline 2575 & Quasi-periodic & $\omega_{w p}$ & $2 X$ & 1.6259 & 1.5890 \\
\hline 3200 & Periodic & $\omega_{w p}$ & $\omega_{w p}$ & 1.0295 & 1.0185 \\
\hline 4000 & Chaotic & $\omega_{w p}-X$ & $X$ & 1.8223 & 1.8389 \\
\hline 4630 & Quasi-periodic & $\omega_{w p}$ & $1.5 X$ & 1.5608 & 1.5118 \\
\hline 5200 & Periodic & $\omega_{w p}$ & $\omega_{w p}$ & 1.0886 & 1.0492 \\
\hline 6235 & Periodic & $\omega_{w p}$ & $\omega_{w p}$ & 1.0844 & 1.0391 \\
\hline 9200 & Periodic & $\omega_{w p}$ & $\omega_{w p}$ & 1.0166 & 1.0197 \\
\hline
\end{tabular}




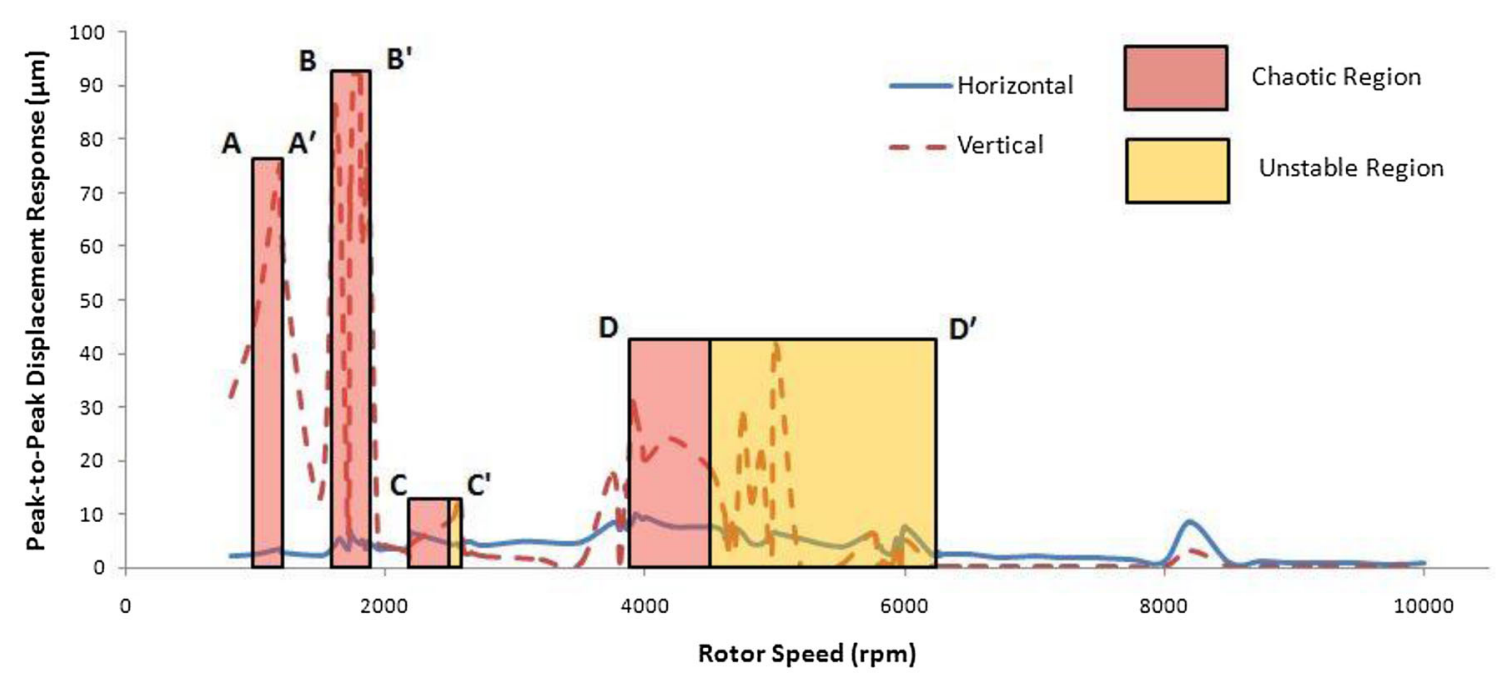

Figure 9. Overall response plot for bearing having an inner race defect.

horizontal and vertical directions and the other major peak is observed at ball passage frequency $\omega_{b p}(309.1 \mathrm{rad} / \mathrm{s})$ in horizontal direction. The HFDs at $3196 \mathrm{rpm}$ are obtained as 1.0165 and 1.0195, respectively, in horizontal and vertical directions. Moreover, the closed orbit Poincaré maps indicate the stability of the system. The third unstable region is identified when the rotor speed is further increased to $3198 \mathrm{rpm}$ and the rotor-bearing system remains in the unstable region up to $3340 \mathrm{rpm}$. Response plots in this region at $3335 \mathrm{rpm}$ are shown in figure 10e, where the peak amplitudes can be noticed at ball passage frequency $\omega_{b p}$ (322.7 rad/s) in both horizontal and vertical directions and other major peaks are observed at $2 \omega_{b p}(645.36 \mathrm{rad} / \mathrm{s})$, $0.5 X(28.03 \mathrm{rad} / \mathrm{s})$ and $X(55.92 \mathrm{rad} / \mathrm{s})$. Here, the system shows a behaviour between periodic and aperiodic solutions and the net-structured shape of Poincaré maps shows the quasi-periodic nature of the system. The HFDs at $3335 \mathrm{rpm}$ are obtained as 1.5469 and 1.5879 , respectively, in horizontal and vertical directions.

With further increment of rotor speed from 3345 to $3590 \mathrm{rpm}$, the periodic nature of Poincaré maps ensures stable nature of the system. Response plots in this stable region at $3590 \mathrm{rpm}$ are shown in figure 10f and peak amplitudes are observed in frequency spectrums at ball passage frequency $\omega_{b p}(345.4 \mathrm{rad} / \mathrm{s})$ in both horizontal and vertical directions. The Poincaré map at $3590 \mathrm{rpm}$ indicates the periodic nature of the system and the HFDs are obtained as 1.0438 and 1.0375 , respectively, in horizontal and vertical directions. Another unstable region is identified as quasi-periodic when the speed is further increased from 3610 to $3760 \mathrm{rpm}$. Response plots in this region at $3760 \mathrm{rpm}$ are shown in figure $10 \mathrm{~g}$ and the net-structured Poincaré maps indicate the quasi-periodic nature of the system. The HFDs are calculated as 1.5984 and 1.5881, respectively, in horizontal and vertical directions. At $3760 \mathrm{rpm}$ the peak amplitudes are noticed at $\omega_{b p}$
(363.6 rad/s) and $1.5 X(90.9 \mathrm{rad} / \mathrm{s})$, respectively, in horizontal and vertical directions and other major peaks are perceived at $2 \omega_{b p}-1.5 X(631.8 \mathrm{rad} / \mathrm{s})$ and $\omega_{b p}(363.5 \mathrm{rad} /$ s) in frequency spectrums.

The system regains its stability with the further increase in speed from 3770 to $5790 \mathrm{rpm}$, having closed orbit Poincaré maps. Response plots in this region at $4750 \mathrm{rpm}$ are shown in figure $10 \mathrm{~h}$, where the peak amplitudes are noticed at $\omega_{b p}(454.5 \mathrm{rad} / \mathrm{s})$. The Poincaré maps show some fractal points on the geometry of closed orbits. The HFDs at $4750 \mathrm{rpm}$ are obtained as 1.0188 and 1.0190, respectively, in horizontal and vertical directions. The system loses its stability again as the speed is further increased from 5815 to $7460 \mathrm{rpm}$ and this region is identified as the fifth unstable region. Response plots in this unstable region at $6000 \mathrm{rpm}$ are shown in figure 10i. In frequency spectrums, the peak amplitudes of vibration are observed at shaft rotational frequency of $\omega_{b p}-0.6 X(513.6 \mathrm{rad} / \mathrm{s})$, where $X$ is due to the interaction effect of ball passage frequency with shaft rotational frequency, and $0.7 X(68.18 \mathrm{rad} / \mathrm{s})$, respectively, in horizontal and vertical directions. The Poincaré maps show the fractal structure and indicate the chaotic response of the system. The nonlinearity of the system is quantified by HFDs and obtained as 1.7188 and 1.7265 , respectively, in horizontal and vertical directions. Further, the system shows the stable nature when the speed is increased beyond $7485 \mathrm{rpm}$, and up to $10000 \mathrm{rpm}$. Response plots in this stable region at $9200 \mathrm{rpm}$ are shown in figure $10 \mathrm{j}$. The response plots indicate the periodic nature of the system having closed orbit Poincaré maps. The peak amplitudes in frequency spectrums are perceived at $\omega_{b p}(877.2 \mathrm{rad} / \mathrm{s})$ in both horizontal and vertical directions. The HFDs for this stable region are obtained as 1.0130 and 1.0239, respectively, in horizontal and vertical directions.

Similar to inner race, in the presence of the defect on outer race, the peak-to-peak amplitude of vibration 

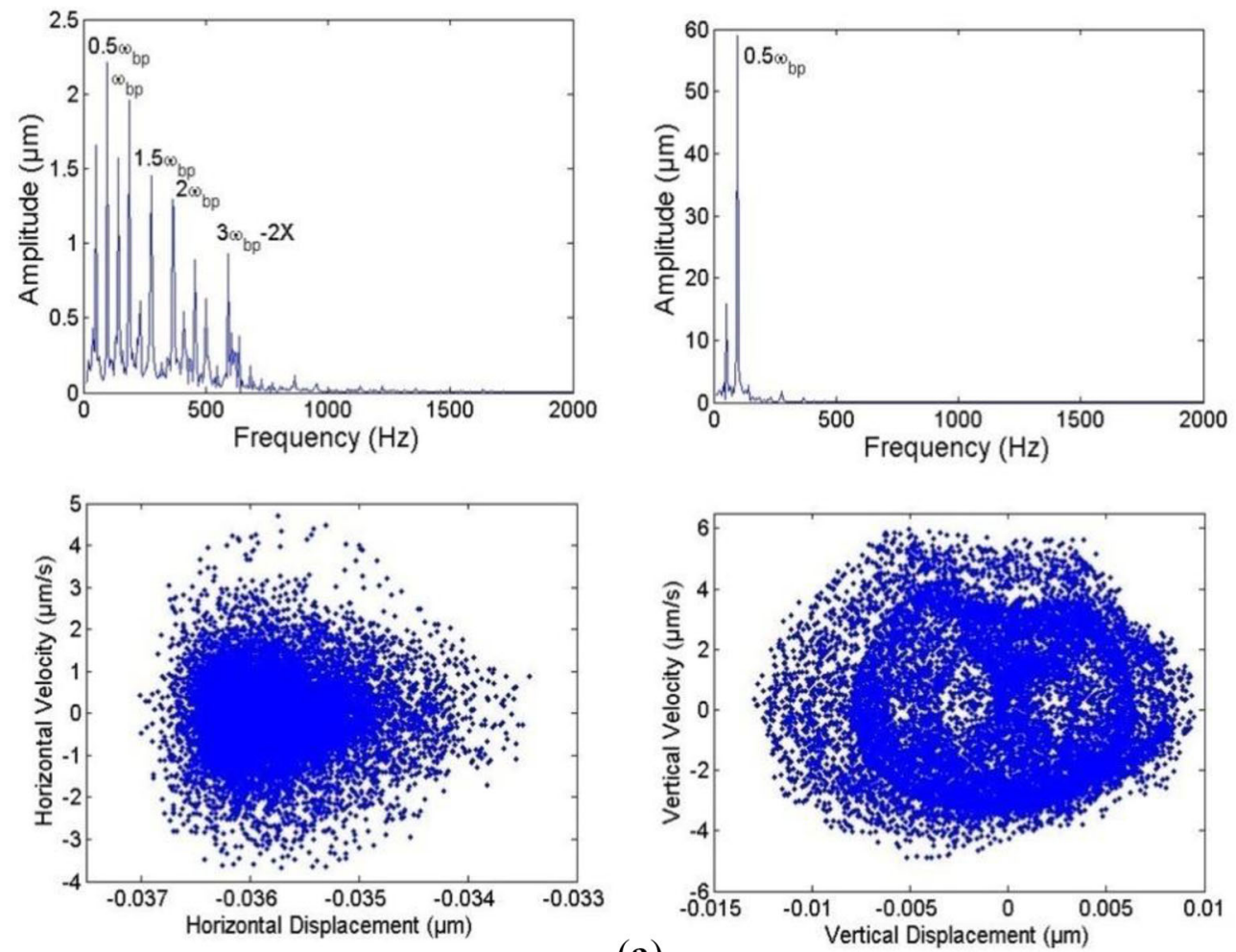

(a)
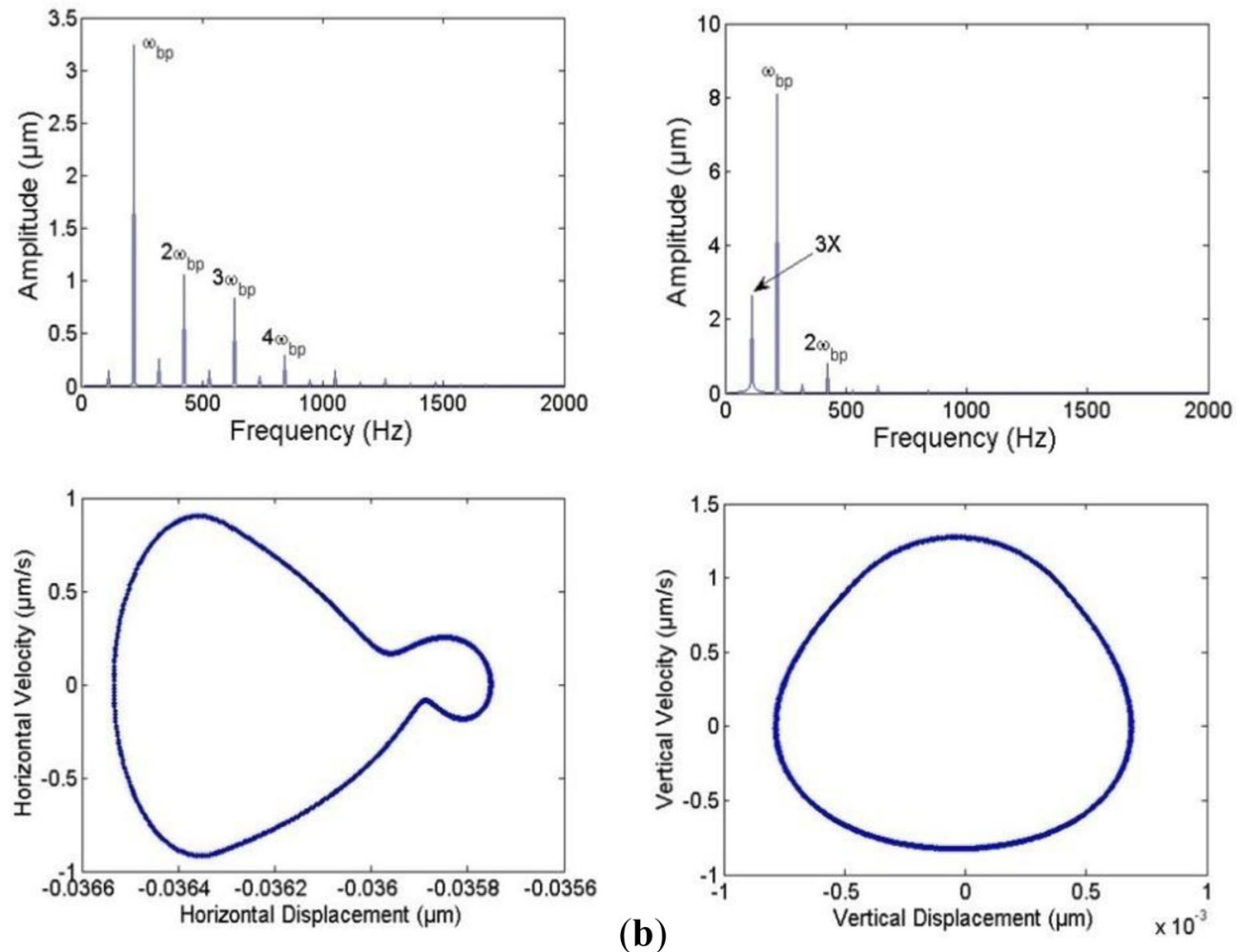

Figure 10. Response plots of bearing having outer race defect at (a) $1900 \mathrm{rpm}$, (b) $2200 \mathrm{rpm}$, (c) $2615 \mathrm{rpm}$, (d) $3196 \mathrm{rpm}$, (e) $3335 \mathrm{rpm}$, (f) $3590 \mathrm{rpm}$, (g) $3760 \mathrm{rpm}$, (h) $4750 \mathrm{rpm}$, (i) $6000 \mathrm{rpm}$ and (j) $9200 \mathrm{rpm}$. 

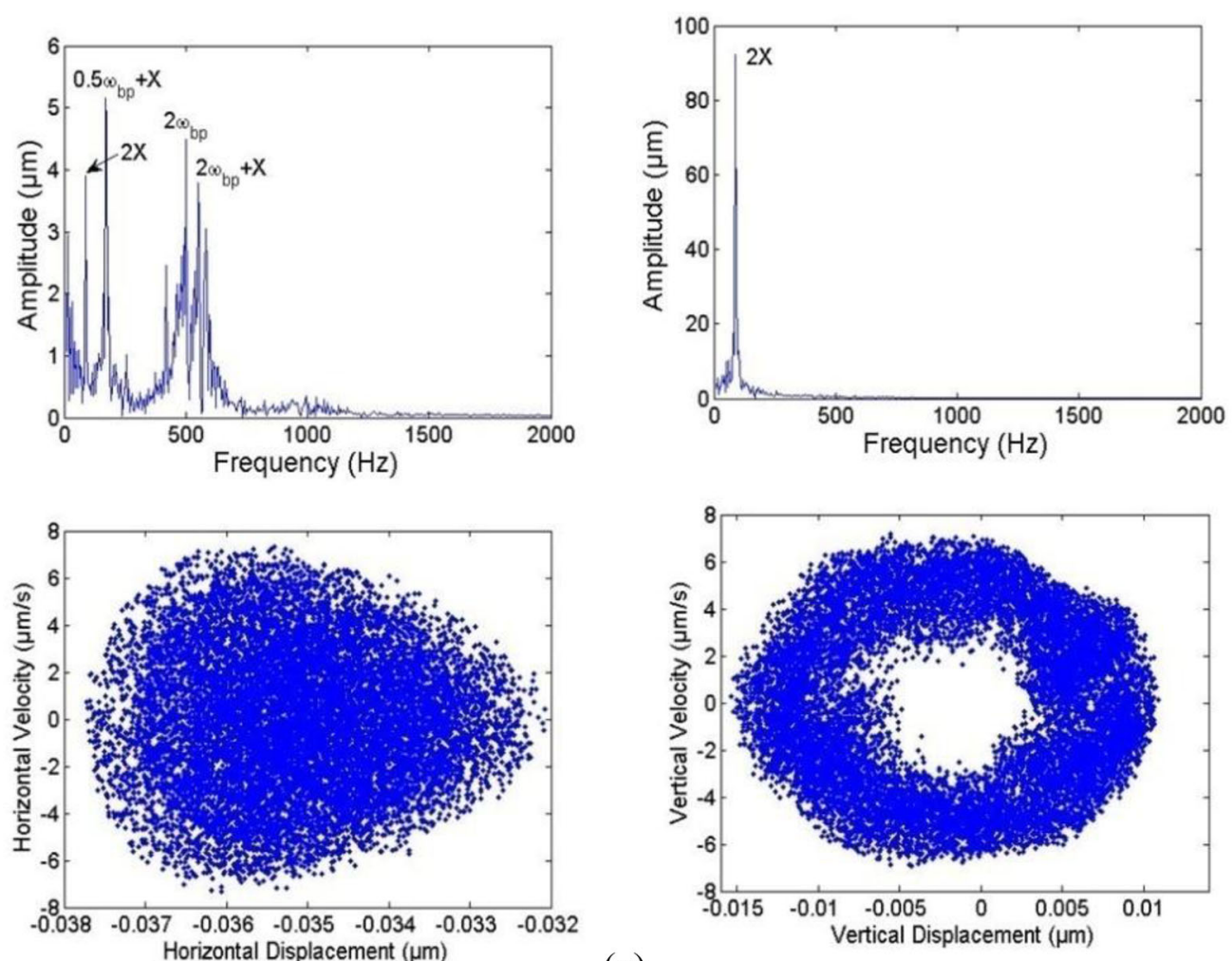

(c)
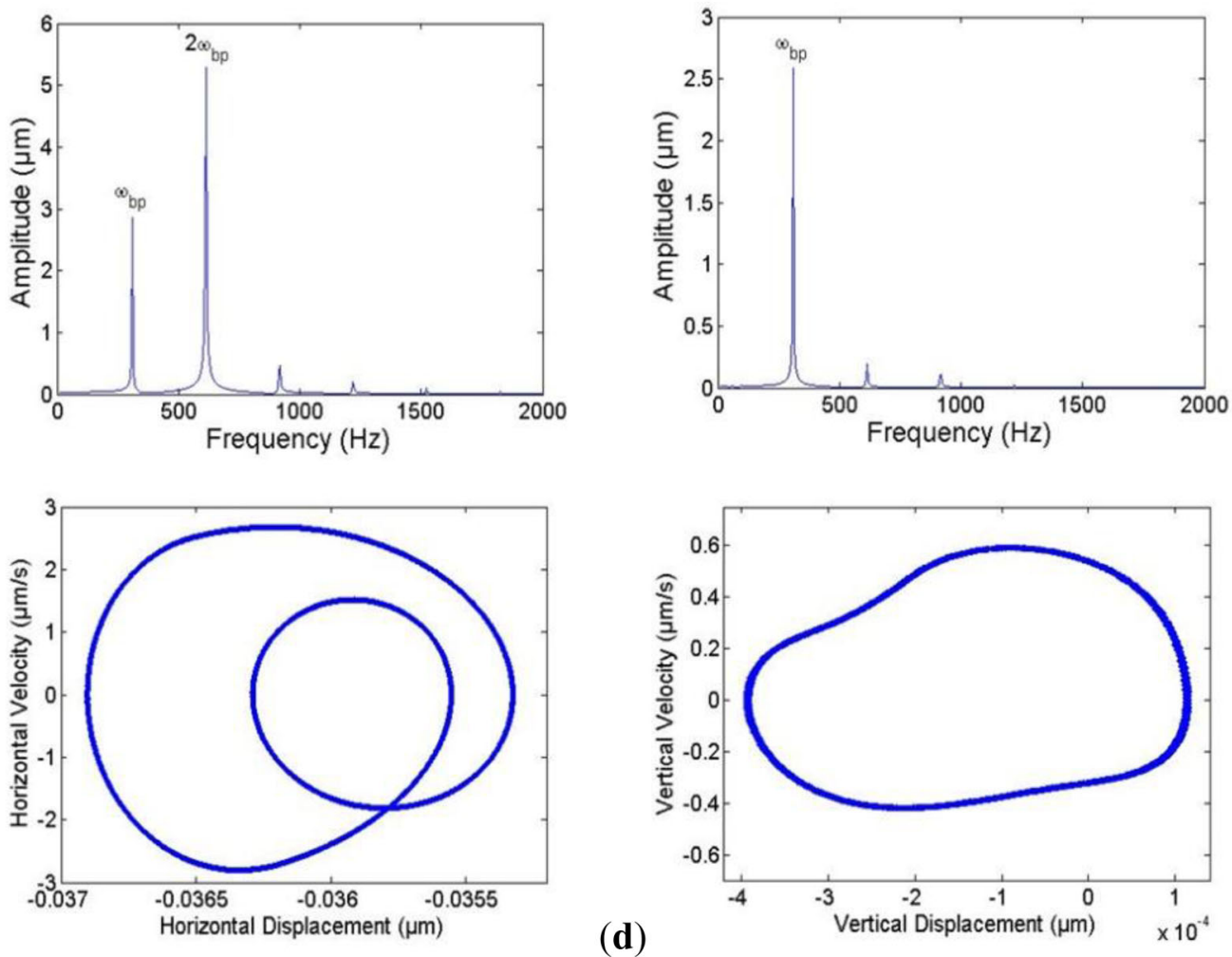

Figure 10. continued

increases significantly. The nature of solution of the system having an outer race defect at various speeds, peak amplitudes and HFDs is summarized in table 4. The overall response of the system having outer race defect is shown in figure 11 and five unstable regions bounded by $\mathrm{A}-\mathrm{A}^{\prime}, \mathrm{B}-\mathrm{B}^{\prime}$, $\mathrm{C}-\mathrm{C}^{\prime}, \mathrm{D}-\mathrm{D}^{\prime}$ and $\mathrm{E}-\mathrm{E}^{\prime}$ are indicated. 

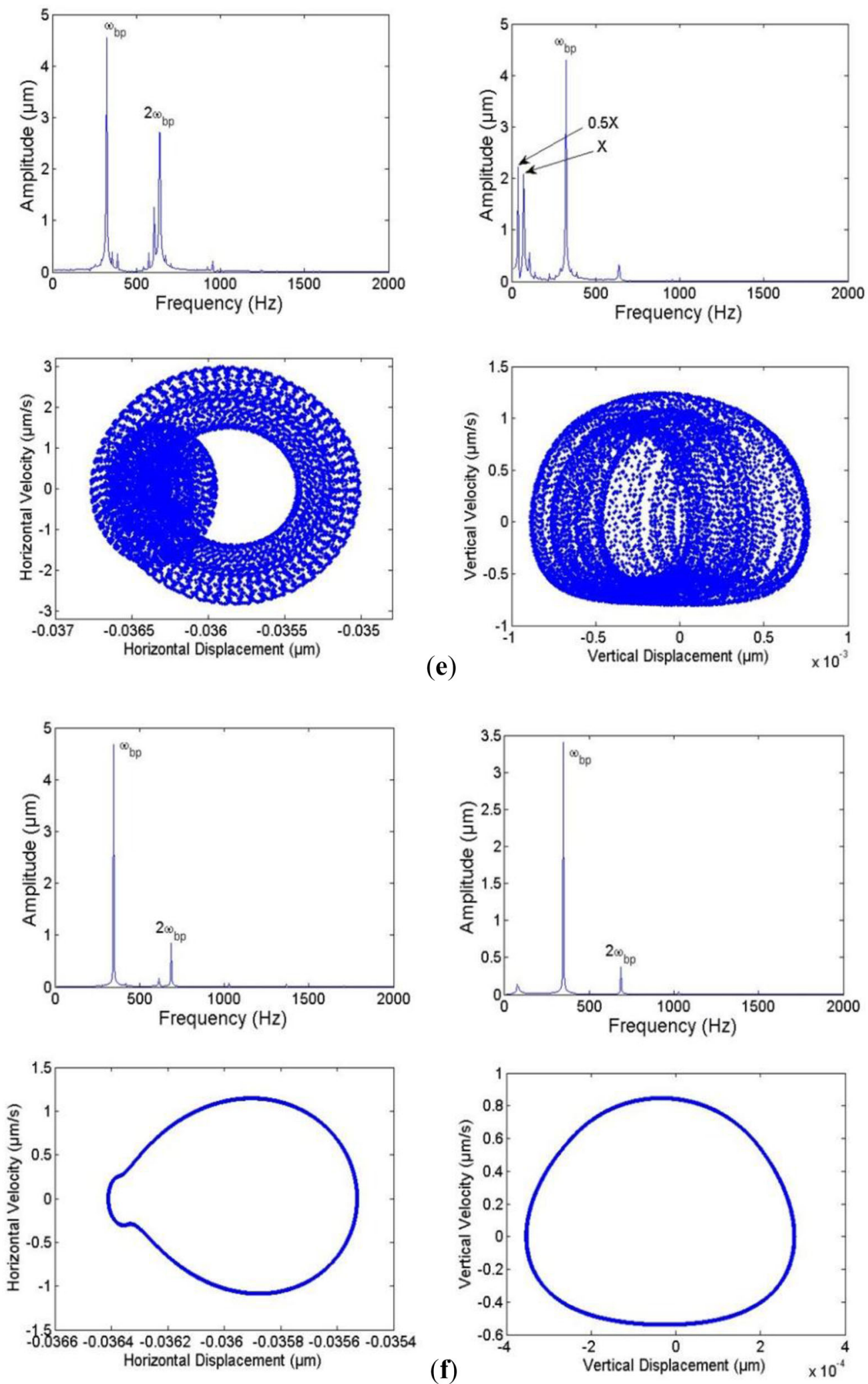

Figure 10. continued 

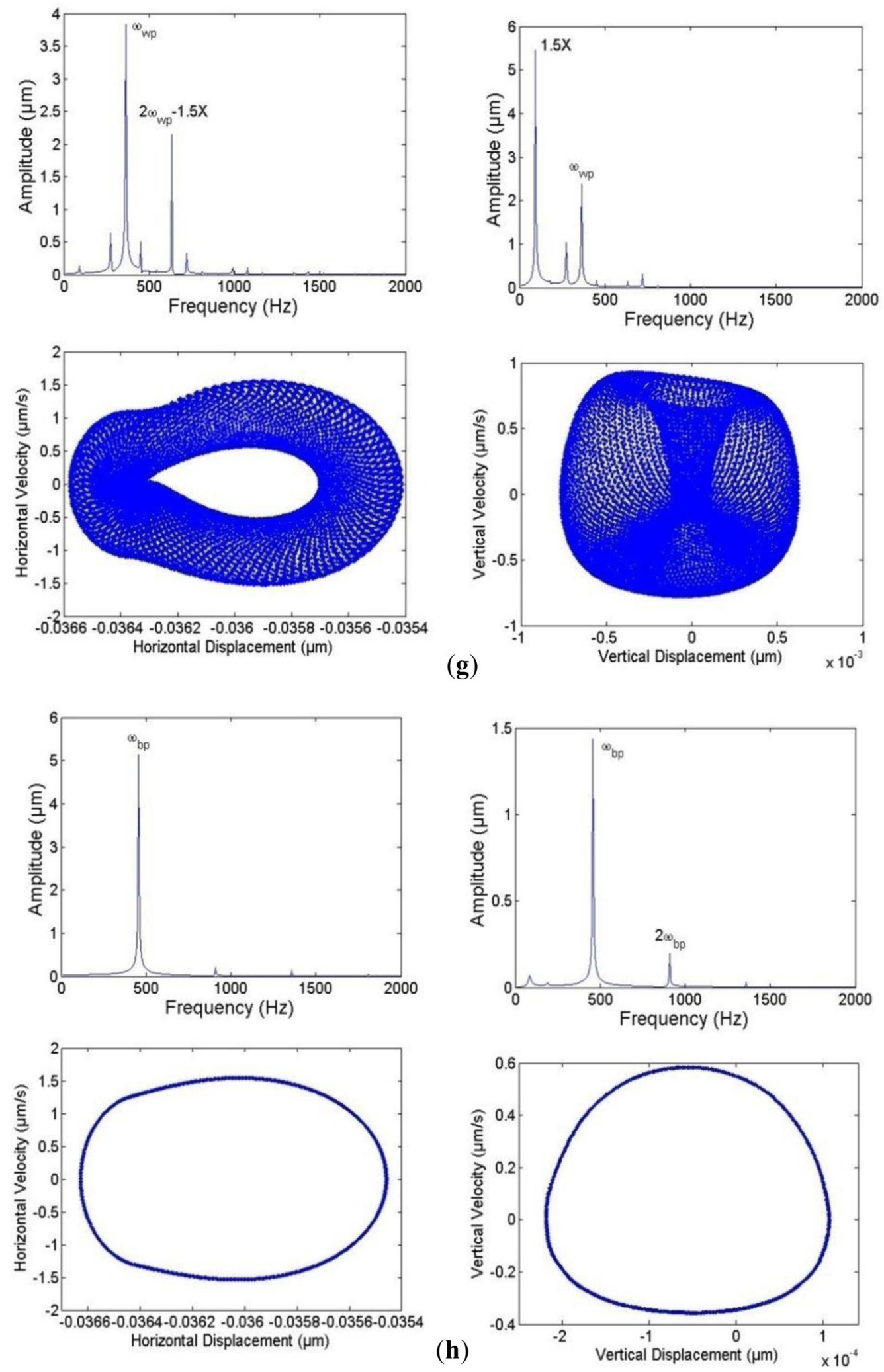

Figure 10. continued 

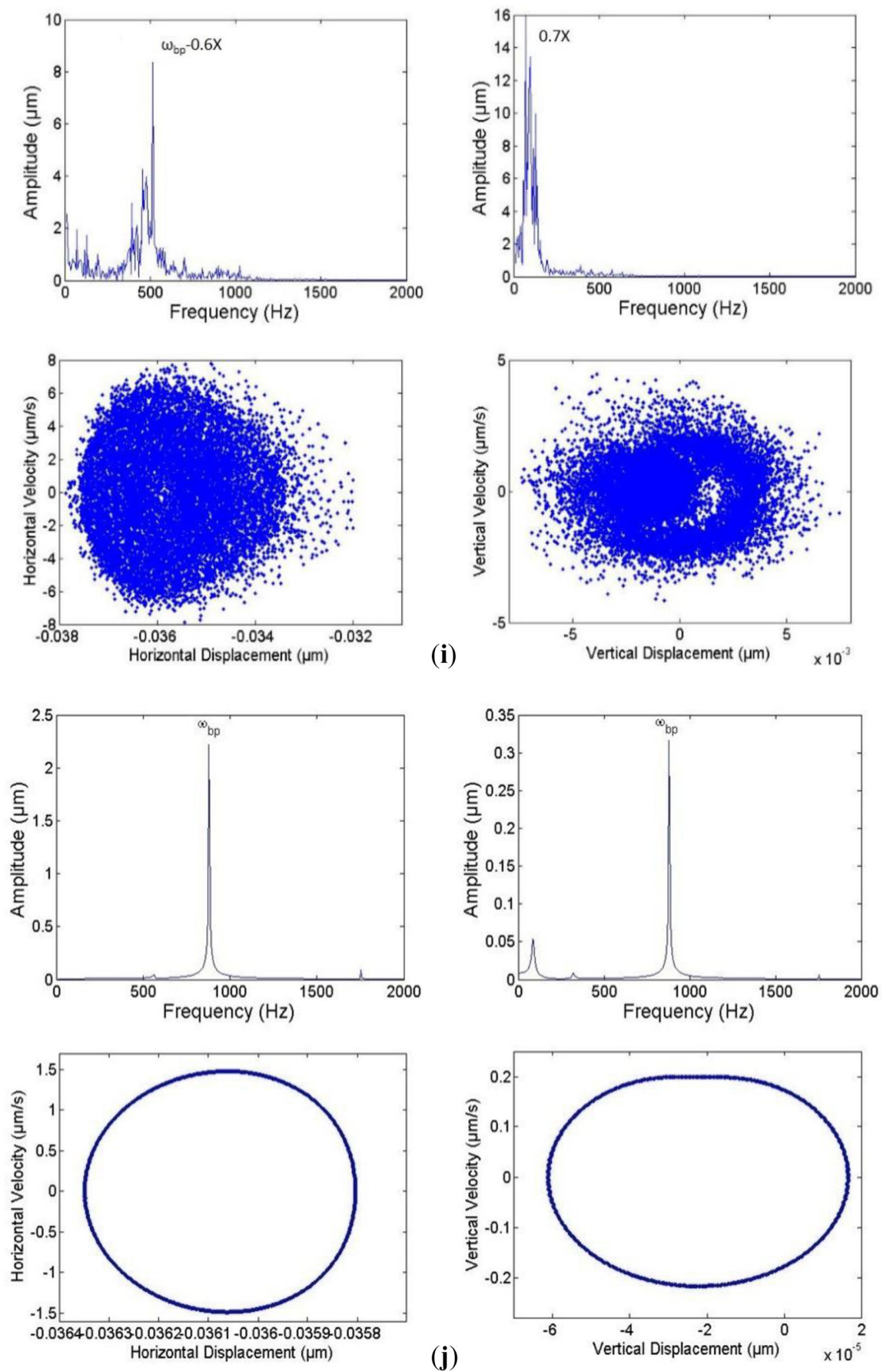

Figure 10. continued 
Table 4. Summary of solutions of bearing having an outer race defect at various speeds.

\begin{tabular}{|c|c|c|c|c|c|}
\hline \multirow[b]{2}{*}{ Speed (rpm) } & \multirow[b]{2}{*}{ Nature of solution } & \multicolumn{2}{|c|}{ Peak amplitude at } & \multicolumn{2}{|c|}{ HFDs } \\
\hline & & Horizontal & Vertical & Horizontal & Vertical \\
\hline 1900 & Chaotic & $0.5 \omega_{b p}$ & $0.5 \omega_{b p}$ & 1.7849 & 1.7795 \\
\hline 2200 & Periodic & $\omega_{b p}$ & $\omega_{b p}$ & 1.0254 & 1.0269 \\
\hline 2615 & Chaotic & $0.5 \omega_{b p}+X$ & $2 X$ & 1.9273 & 1.9085 \\
\hline 3196 & Periodic & $2 \omega_{b p}$ & $\omega_{b p}$ & 1.0165 & 1.0915 \\
\hline 3335 & Quasi-periodic & $\omega_{b p}$ & $\omega_{b p}$ & 1.5469 & 1.5879 \\
\hline 3590 & Periodic & $\omega_{b p}$ & $\omega_{b p}$ & 1.0438 & 1.0375 \\
\hline 3760 & Quasi-periodic & $\omega_{b p}$ & $1.5 X$ & 1.5984 & 1.5881 \\
\hline 4750 & Periodic & $\omega_{b p}$ & $\omega_{b p}$ & 1.0188 & 1.0190 \\
\hline 6000 & Chaotic & $\omega_{b p}-0.5 X$ & $0.5 X$ & 1.7188 & 1.7265 \\
\hline 9200 & Periodic & $\omega_{b p}$ & $\omega_{b p}$ & 1.0130 & 1.0239 \\
\hline
\end{tabular}

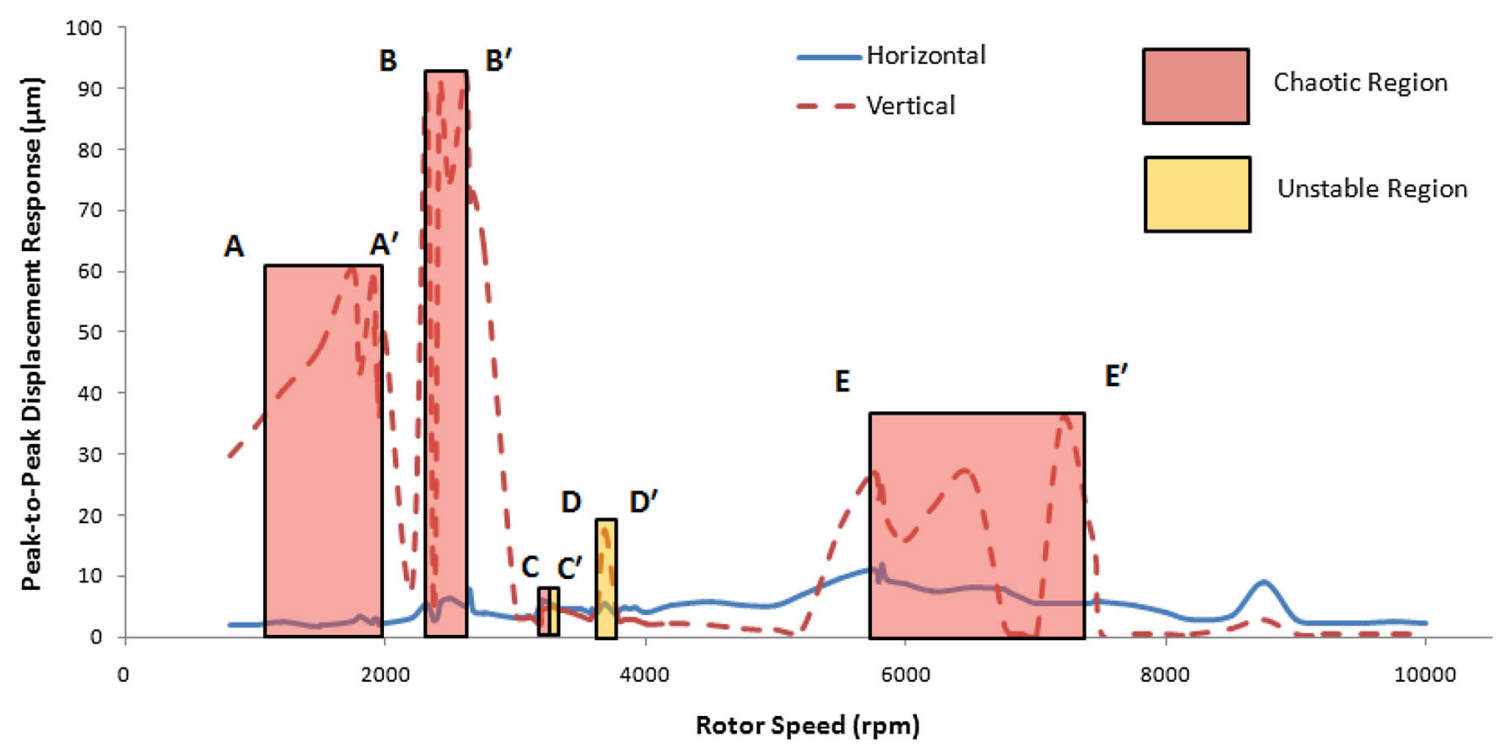

Figure 11. Overall response plot for bearing having an outer race defect.

\section{Conclusions}

In the present study, theoretical study has been carried out to examine the nonlinear vibration responses of an unbalanced rotor-roller bearing system. The responses of healthy and faulty bearings are analysed at various rotating speeds. The concept of HFD is used to study the nonlinear dynamic behaviour of the system. Following conclusions are drawn from the study;

- The healthy rotor-bearing system has four unstable regions with high amplitudes of vertical vibrations. This is due to the change in Hopf bifurcation with speed variation.

- The responses of the system having spalled inner and outer races show high rough appearance specifically between 3900 and $7500 \mathrm{rpm}$, with higher amplitudes of vertical vibrations. Also, the system has low peakto-peak amplitudes of vibration at higher speeds.
- Chaotic nature of responses is observed to be associated with the spalled outer race. In other words, the overall response of the system depicts more unstable/chaotic regions in the presence of defects over the outer race surface. These unstable regions have a strong chaotic attractor compared with a healthy bearing and a bearing having inner race defect, and also have $1-\mathrm{T}$ and perioddoubling solutions.

- Qualitative and quantitative assessments of nonlinearity of the rotor-bearing system have been performed and both establish the stable and unstable regions well. HFDs are successfully employed to identify and quantify the unstable regions. It can be used as a powerful tool to quantify the nonlinearity and helps the designers to deal with unstable regions more precisely.

- HFDs can also be used as a diagnostic tool for health monitoring of the rotor-bearing system and maintenance strategies can be planned accordingly in the presence of defects. 


\section{Nomenclature}

$N$ number of observations in time series data

$F D_{\text {est }}$ estimated FD of the signal

$F D_{t h}$ theoretical FD of the signal

$k$ nonlinear stiffness, $\mathrm{N} / \mathrm{mm}$

$L_{\mathrm{u}} \quad$ useful length of the roller, $\mathrm{mm}$

$\delta$ deformation of the roller at contact points, $\mathrm{mm}$

$Q \quad$ contact force, $\mathrm{N}$

$W \quad$ vertical radial load, $\mathrm{N}$

$F_{\theta_{j}} \quad$ contact force at $j^{\text {th }}$ roller, N

$\theta_{j} \quad$ angular position of the $j^{\text {th }}$ roller, radian

$R_{\text {cr }} \quad$ radial clearance, $\mathrm{mm}$

$X, Y \quad$ state space variable

$\overrightarrow{P_{d_{j}}} \quad$ nonlinear dissipative force, $\mathrm{N}$

$U_{f} \quad$ unbalanced force, $\mathrm{N}$

$N_{r} \quad$ number of rollers

$\omega_{c g}$ angular velocity of the cage, $\mathrm{rad} / \mathrm{s}$

$\omega_{\text {ir }} \quad$ angular velocity of the inner $\mathrm{race}, \mathrm{rad} / \mathrm{s}$

$\delta_{s} \quad$ additional deflection due to defect (spall), $\mathrm{mm}$

$R_{i r} \quad$ radius of the inner race, $\mathrm{mm}$

$R_{\text {or }} \quad$ radius of the outer race, $\mathrm{mm}$

$d w \quad$ defect width, $\mathrm{mm}$

$\phi_{d i r} \quad$ angle of defect corresponding to inner race, radian

$\phi_{d o r}$ angle of defect corresponding to outer race, radian

\section{Appendix A}

For a rolling element bearing, having rotating inner race, various corresponding frequencies are

$$
\text { cage frequency }\left(\omega_{c}\right)=\frac{\omega_{s}}{2}\left[1-\left(\frac{d}{D}\right) \cos \beta\right] \mathrm{rad} / \mathrm{s}
$$

outer race malfunction frequency or ball passage frequency

$$
\left(\omega_{b p}\right)=\frac{N_{r} \omega_{s}}{2}\left[1-\left(\frac{d}{D}\right) \cos \beta\right] \mathrm{rad} / \mathrm{s}
$$

inner race malfunction frequency or wave passage frequency

$$
\left(\omega_{w p}\right)=\frac{N_{r} \omega_{s}}{2}\left[1+\left(\frac{d}{D}\right) \cos \beta\right] \mathrm{rad} / \mathrm{s}
$$

and rolling element malfunction frequency or rolling element spin frequency or wave passage frequency of rolling element

$$
\left(\omega_{w p b}\right)=\frac{D \omega_{s}}{d}\left[1-\left(\frac{d^{2}}{D^{2}}\right) \cos ^{2} \beta\right] \mathrm{rad} / \mathrm{s}
$$

where $N_{r}$ is a number of rolling elements, $\omega_{s}$ is shaft rotational frequency, $d$ is rolling element diameter, $D$ is pitch circle diameter and $\beta$ is contact angle.

\section{References}

[1] Sharma A, Upadhyay N, Kankar P K and Amarnath M 2018 Nonlinear dynamic investigations on rolling element bearings: a review. Adv. Mech. Eng. 10: 1-15

[2] Gupta P K 1979 Dynamics of rolling element bearings-part I: cylindrical roller bearing analysis. J. Lubr. Technol. Trans. ASME 101: 293-304

[3] Gupta P K 1979 Dynamics of rolling element bearings-part II: cylindrical roller bearing results. J. Lubr. Technol. Trans. ASME 101: 305-311

[4] McFadden P D and Smith J D 1984 Model for the vibration produced by a single point defect in a rolling element bearing. J. Sound Vib. 96: 69-82

[5] McFadden P D and Smith J D 1985 The vibration produced by multiple point defects in a rolling element bearing. $J$. Sound Vib. 98: 263-273

[6] Tandon N and Choudhury A 1997 An analytical model for the prediction of the vibration response of rolling element bearings due to a localized defect. J. Sound Vib. 205: 275-292

[7] Tiwari M and Gupta K 2000 Dynamic response of an unbalanced rotor supported on ball bearings. J. Sound Vib. 238: 757-779

[8] Harsha S P 2005 Nonlinear dynamic analysis of an unbalanced rotor supported by roller bearing. Chaos Soliton Fract. 26: 47-66

[9] Lioulios A N and Antoniadis I A 2006 Effect of rotational speed fluctuations on the dynamic behaviour of rolling element bearings with radial clearances. Int. J. Mech. Sci. 48: 809-829

[10] Harsha S P, Nataraj C and Kankar P K 2006 The effect of ball waviness on nonlinear vibrations associated with rolling element bearings. Int. J. Acoust. Vib. 11: 56-66

[11] Kankar P K, Sharma S C and Harsha S P 2011 Fault diagnosis of high speed rolling element bearings due to localized defects using response surface method. J. Dyn. Syst. Meas. Control Trans. ASME 133: 031007-1-14

[12] Arslan H and Aktürk N 2008 An investigation of rolling element vibrations caused by local defects. J. Tribol. Trans. ASME 130: 041101-1-12

[13] Ashtekar A, Sadeghi F and Stacke L 2008 A new approach to modeling surface defects in bearing dynamics simulations. $J$. Tribol. Trans. ASME 130: 041103-1-8

[14] Patil M S, Mathew J, Rajendrakumar P K and Desai S 2010 A theoretical model to predict the effect of localized defect on vibrations associated with ball bearing. Int. J. Mech. Sci. 52: 1193-1201

[15] Leblanc A, Nelias D and Defaye C 2009 Nonlinear dynamic analysis of cylindrical roller bearing with flexible rings. $J$. Sound Vib. 325: 145-160

[16] Sinou J J 2009 Non-linear dynamics and contacts of an unbalanced flexible rotor supported on ball bearings. Mech. Mach. Theory 44: 1713-1732

[17] Bai C, Zhang H and Xu Q 2010 Experimental and numerical studies on nonlinear dynamic behaviour of rotor system supported by ball bearings. J. Eng. Gas Turbines Power 132: 082502-1-5

[18] Patel V N, Tandon N and Pandey R K 2010 A dynamic model for vibration studies of deep groove ball bearings 
considering single and multiple defects in races. J. Tribol. Trans. ASME 132: 041101-1-10

[19] Ghafari S H, Abdel-Rahman E M, Golnaraghi F and Ismail F 2010 Vibrations of balanced fault-free ball bearings. J. Sound Vib. 329: 1332-1347

[20] Kankar P K, Sharma S C and Harsha S P 2012 Vibration based performance prediction of ball bearings caused by localized defects. Nonlinear Dyn. 69: 847-875

[21] Shao Y, Liu J and Ye J 2014 A new method to model a localized surface defect in a cylindrical roller-bearing dynamic simulation. Proc. Inst. Mech. Eng. J. J. Eng. Tribol. 228: $140-159$

[22] Sharma A, Amarnath M and Kankar P K 2014 Effect of varying the number of rollers on dynamics of a cylindrical roller bearing. In: Proceedings of the ASME 2014 International Design and Engineering Technical Conferences and Computers and Information in Engineering Conference (IDETC/CIE 2014), vol. 8: 26th Conference on Mechanical Vibration and Noise, Buffalo, New York, USA, August 17-20, Paper no. DETC2014-34824: V008T11A067, 8 pages

[23] Logan D and Mathew J 1996 Using the correlation dimension for vibration fault diagnosis of rolling element bearingsI: basic concepts. Mech. Syst. Signal Process. 10: 241-250

[24] Logan D and Mathew J 1996 Using the correlation dimension for vibration fault diagnosis of rolling element bearingsII: selection of experimental parameters. Mech. Syst. Signal Process. 10: 251-264

[25] Jiang J D, Chen J and Qu L S 1999 The application of correlation dimension in gearbox condition monitoring. $J$. Sound Vib. 223: 529-541

[26] Yang J, Zhang Y and Zhu Y 2007 Intelligent fault diagnosis of rolling element bearing based on SVMs and fractal dimension. Mech. Syst. Signal Process. 21: 2012-2024

[27] Ghafari S H, Golnaraghi F and Ismail F 2008 Effect of localized faults on chaotic vibration of rolling element bearings. Nonlinear Dyn. 53: 287-301

[28] Kappaganthu K and Nataraj C 2011 Nonlinear modeling and analysis of a rolling element bearing with a clearance. Commun. Nonlinear Sci. Numer. Simul. 16: 4134-4145

[29] Gupta T C, Gupta K and Sehgal D K 2011 Instability and chaos of a flexible rotor ball bearing system: an investigation on the influence of rotating imbalance and bearing clearance. J. Eng. Gas Turbines Power 133: 082501-11

[30] Sharma A, Amarnath M and Kankar P K 2015 Effect of unbalanced rotor on the dynamics of cylindrical roller bearings. In: Mechanisms and Machine Science, Proceedings of the 9th IFToMM International Conference on Rotor
Dynamics, Milan, Italy, September 22-25, Switzerland: Springer International Publishing, vol. 21, pp. 1653-1663

[31] Sarkar N and Chaudhuri B B 1992 An efficient approach to estimate fractal dimension of textural images. Pattern Recogn. 25: 1035-1041

[32] Huang Q, Lorch J R and Dubes R C 1994 Can the fractal dimension of images be measured? Pattern Recogn. 27: 339-349

[33] Esteller R, Vachtsevanos G, Echauz J and Litt B 2001 A comparison of waveform fractal dimension algorithms. IEEE Trans. Circuits-I 48: 177-183

[34] Polychronaki G E, Ktonas P Y, Gatzonis S, Siatouni A, Asvestas P A, Tsekou H, Sakas D and Nikita K S 2010 Comparison of fractal dimension estimation algorithms for epileptic seizure onset detection. J. Neural Eng. 7: 1-18

[35] Upadhyay R, Manglick A, Reddy D K, Padhy P K and Kankar P K 2015 Channel optimization and nonlinear feature extraction for electroencephalogram signals classification. Comput. Electr. Eng. 45: 222-234

[36] Mandelbrot B B 1967 How long is the coast of Britain? Statistical self-similarity and fractional dimension. Science 156: 636-638

[37] Higuchi T 1988 Approach to an irregular time series on the basis of the fractal theory. Physica D 31: 277-283

[38] Petrosian A 1995 Kolmogorov complexity of finite sequences and recognition of different preictal EEG patterns. In: Proceedings of the Eighth IEEE Symposium on ComputerBased Medical Systems, Lubbock, Texas, USA, June 9-10, pp. 212-217

[39] Katz M 1988 Fractals and the analysis of waveforms. Comput. Biol. Med. 18: 145-156

[40] Kantelhardt J W, Zschiegner S A, Koscielny-Bunde E, Havlin S, Bunde A and Stanley H E 2002 Multifractal detrended fluctuation analysis of nonstationary time series. Physica A 316: 87-114

[41] Chang-Jian C W 2010 Strong nonlinearity analysis for gearbearing system under nonlinear suspension-bifurcation and chaos. Nonlinear Anal. Real World Appl. 11: 1760-1774

[42] Brändlein J, Eschmann P, Hasbargen L and Weigand K 2000 Ball and roller bearings: theory, design and application, $3 \mathrm{rd}$ ed. Chichester: Wiley

[43] Wensing J A 1998 On the dynamics of ball bearings. $\mathrm{PhD}$ Thesis, University of Twente, Enschede, The Netherlands

[44] Kuhnell B T 2004 Wear in rolling element bearings and gears-how age and contamination affect them. Mach. Lubr. 9. https://www.machinerylubrication.com/Read/664/wearbearings-gears 